Tinbergen Institute Discussion Paper

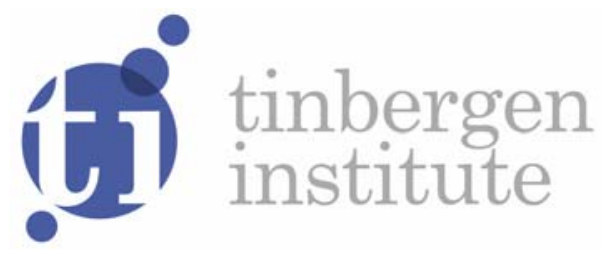

\title{
Collective Labour Supply, Taxes, and Intrahousehold Allocation: An Empirical Approach
}

Hans Bloemen

Faculty of Economics and Business Administration, VU University Amsterdam, and Tinbergen Institute, the Netherlands. 
Tinbergen Institute is the graduate school and research institute in economics of Erasmus University Rotterdam, the University of Amsterdam and VU University Amsterdam.

More TI discussion papers can be downloaded at http://www.tinbergen.nl

Tinbergen Institute has two locations:

Tinbergen Institute Amsterdam

Gustav Mahlerplein 117

1082 MS Amsterdam

The Netherlands

Tel.: +31(0)20525 1600

Tinbergen Institute Rotterdam

Burg. Oudlaan 50

3062 PA Rotterdam

The Netherlands

Tel.: +31(0)10 4088900

Fax: +31(0)10 4089031 


\title{
Collective Labour Supply, Taxes, and Intrahousehold Allocation: An Empirical Approach
}

\author{
by \\ Hans G. Bloemen ${ }^{1}$ \\ Department of Economics \\ Vrije Universiteit Amsterdam and Tinbergen Institute \\ De Boelelaan 1105 \\ 1081 HV Amsterdam \\ The Netherlands
}

October 2015

Keywords: Labour supply, Household behaviour and Family Economics, Intrahousehold allocation, Taxation, Model construction and estimation JEL code: J22, D1, D13, H24, C51

\begin{abstract}
Most empirical studies of the impact of labour income taxation on the labour supply behaviour of households use a unitary modelling approach. In this paper we empirically analyze income taxation and the choice of working hours by combining the collective approach for household behaviour and the discrete hours choice framework with fixed costs of work. We identify the sharing rule parameters with data on working hours of both the husband and the wife within a couple. Parameter estimates are used to evaluate various model outcomes, like the wage elasticities of labour supply and the impacts of wage changes on the intrahousehold allocation of income. We also simulate the consequences of a policy change in the tax system. We find that the collective model has different empirical outcomes of income sharing than a restricted model that imposes income pooling. In particular, a specification with income pooling fails to capture asymmetries in the income sharing across spouses. These differences in outcomes have consequences for the evaluation of policy changes in the tax system and shed light on the effectiveness of certain policies.
\end{abstract}

\footnotetext{
${ }^{1}$ We are greatly indebted to Statistics Netherlands for providing the data. Other affiliations: IZA, Bonn; Netspar. Email: h.g.bloemen@vu.nl, phone: +31 20 5986037, fax: +31 20 5986005. An earlier version of this paper circulated under the title "Income taxation in an empirical collective household labour supply model with discrete hours".
} 


\section{Introduction}

The empirical literature on labour supply has devoted much attention to the evaluation of the impact of the income tax system on the choice of working hours and participation. ${ }^{2}$ The focus of the analysis has been increasingly directed towards the joint labour supply decision of couples. ${ }^{3}$ Studies known in the literature almost invariably use the unitary model of household labour supply for this analysis. The unitary approach assumes the existence of a household utility function, and does not specify the preferences of the individual household members. Therefore, the intrahousehold allocation process is ignored and the unitary model provides no conclusions about the process of income sharing between household members as income pooling is imposed. Labour supply studies that have tested for the restrictions of the unitary model on the labour supply of household members, like for instance the pooling restriction, almost invariably reject the unitary restrictions. ${ }^{4}$ Moreover, policy makers often target policy instruments to specific individuals within a household. Within a unitary framework, the intrahousehold implications of such instruments cannot be revealed. ${ }^{5}$

McElroy and Horney (1981) formulated a household decision model that allows for individual preferences of household members, and specifies a Nash bargaining process between husband and wife. The approach by Apps and Rees (1988) only needs the assumption of efficiency, whereas the specification of an explicit bargaining rule is not required. Chiappori (1988, 1992) formulates a collective model of household labour supply. The collective model explicitly specifies the preferences of the individual household members, and assumes Pareto efficient bargaining between household members. Chiappori (1988, 1992) showed that under certain conditions, like egoistic (or caring) preferences and the absence of a public good in the household, a sharing rule can be identified up to an additive constant. The sharing rule specifies the allocation of income between household members. The underlying individual preference parameters can be identified.

\footnotetext{
2 See e.g. Blundell and MaCurdy (1999) for an overview.

3 See e.g. Hausman and Ruud (1984), and Van Soest (1995), Hoynes (1996), Keane and Moffit (1998), and Blundell et al. (1999).

${ }^{4}$ In these studies the tax system is not incorporated explicitly. See e.g. Fortin and Lacroix (1997) for an extensive test of the unitary model, and Thomas (1990) for a test of income pooling.

${ }^{5}$ See Vermeulen (2002) for a discussion of the unitary framework versus the collective model.
} 
The empirical implementation of the collective model involves some complications, which explains why studies on household labour supply and taxes mostly employ the unitary model, as discussed by Beninger and Laisney (2002). In the collective model it is less straightforward to incorporate the participation decision and taxation. Recently, Blundell et al. (2007) and Donni (2003) extended the identification result of the sharing rule to include the case of nonparticipation by one of the partners. Bloemen (2010) specifies an empirical model of collective household labour supply which allows for nonparticipation.

Donni (2003) derives conditions for the implementation of a nonlinear but convex budget constraint in a collective model. In particular, he shows that the parameters of the sharing rule can be recovered from the labour supply functions that are based on virtual wage rates and virtual nonlabour income. His approach is based on the availability of an explicit expression of the labour supply function (conditional on the tax bracket) and therefore may be interpreted as a collective version of the Hausman and Ruud (1984) approach. Bargain and Moreau (2003) simulate a collective model with taxes and show the implications of using the collective approach for various model outcomes. Beninger and Laisney (2002) simulate data from a specification of the collective model and show how changes in the tax system affect model outcomes. They also estimate a discrete hours choice model, similar to Van Soest (1995), with simulated collective data, to see whether the unitary model generates results that are comparable to the collective model from which the data were generated. The unitary model generates substantially different results than the collective model. ${ }^{6}$ Vermeulen (2006) used the discrete hours choice model to empirically implement taxes in a collective type of model. His focus is on couples with husbands in full-time employment. Vermeulen et al. (2006) suggest a calibration approach for modelling collective labour supply with income taxes. Their identification strategy, though, is based on comparing married and single women. ${ }^{7}$

\footnotetext{
${ }^{6}$ It should be noted that there may be several causes for the differences between the outcomes, like the use of different utility functions, the use of a discrete choice framework, as well as the specification with the logistic errors. For instance, Beninger and Laisney (2002) find that the model underestimates the probability of nonparticipation, which was also found in the original discrete hours model, even when it is extended with fixed cost of work.

${ }^{7}$ The study by Vermeulen et al. (2006) is included in an issue of Review of Economics of the Household (2006, Volume 4, Number 2) that is completely devoted to the collective model. However, since this promising initiative most studies on labour supply and taxation still employ the unitary framework, ignoring the
} 
In this study we specify an implementable empirical model of household labour supply with taxes that can be estimated with labour supply data for both husband and wife, is based on individual preferences, and does not a priori impose income pooling, such that it can be used for evaluating the household's income sharing process. We aim to identify sharing rule parameters and preferences by using data of husband and wife within couples, rather than by relying on equality of preference parameters for single and married females, ${ }^{8}$ since the restrictions of the collective model set in the original model (Chiappori 1988, 1992) actually are restrictions between the husband's and wife's labour supply. For reasons of flexibility and implementability, we use a discrete hours choice approach. Van Soest (1995) used the discrete model in the context of a unitary household labour supply model.

Our approach does not fully comply with the theoretical literature on collective models. In particular, we relax some regularity conditions which are necessary for uniqueness of the labour supply outcomes of spouses. Donni (2003) proves the unique identification of the sharing rule from male and female working hours under the condition of a convex budget set, which precludes nonconvexities in the tax system and the presence of fixed costs. Most tax systems, though, contain nonconvexities, often generated by tax credits, and generally, when it comes to income taxation and labour supply, the most interesting policy issues are concentrated around these nonconvexities. In the empirical labour supply literature the presence of fixed costs is recognized as an important mechanism to explain differences in hours responses at the intensive and the extensive margin. To comply with the existing theory about collective models requires convexification of the budget set, and the neglecting of fixed costs. Moreover, it requires working with utility functions that satisfy all regularity conditions. The most well-known functional forms for utility functions that satisfy regularity conditions and are still reasonably well to manage in a setting with taxation are quite restrictive. ${ }^{9}$ This raises the question whether the 'collective model' is still implementable and applicable to real-world problems. The aim of this paper is to provide an empirical approach which allows us to draw conclusions about the intrahousehold allocation mechanism, and

implications of tax instruments for the intrahousehold allocation.

8 The fact that some persons are single and others part of a couple may be related to differences in preferences for the formation of couples (see Manser and Brown, 1980).

${ }^{9}$ See, for instance, Bloemen and Kapteyn, 2008, for a discussion. 
to see how the effectiveness of tax policies is affected by this mechanism, by estimating the sharing rule parameters from restrictions across partners, using flexible preferences ${ }^{10}$ and incorporating complex tax systems.

To allow for flexible preferences and complex tax systems, we will employ the discrete hours labour supply model that is specifically suitable to deal with non-convex budget sets. The functional form of the utility function is generally quadratic and does not a priori satisfy regularity conditions. A direct application of this approach in the context of the collective model therefore does not a priori impose the regularity conditions as found in the theory on collective models. Not complying with these conditions has implications for the uniqueness of the model's solution. In formulating the model's likelihood function, this pops up, not as an identification problem, but as a coherency problem. That means that for a given set of parameter values, there can be more than one combination of male-female working hours that satisfies the equilibrium conditions. The equilibrium is not uniquely determined and the implication for full information maximum likelihood estimation is that the probabilities over all choice alternatives (which are combinations of male-female working hours) need not (exactly) add up to one. Estimation based on the full information maximum likelihood function will therefore lead to inconsistent estimates. The reason for this is that the underlying economic model is incomplete and requires an additional rule to select between different equilibria. Our estimation strategy is such that we will not impose any additional structure on the economic framework. In the data we observe only one outcome for each couple, and that is informative about the underlying preferences and income sharing mechanism. The full model does not provide a unique outcome, but given the number of working hours of their spouse, each individual's number of working hours is unique. That implies that the (partial) likelihood function given the spouse's working hours satisfies regularity conditions, and we can use the partial likelihood functions to consistently estimate the model parameters. Cross equation restrictions between the labour supply choices of partners can be used to identify the parameters of the income sharing mechanism. Thus, rather than fully complying with the 'collective model', which limits the empirical applicability, our estimation strategy

\footnotetext{
10 The need for the specification of flexible preferences in the context of collective labour supply model was already recognized by Fortin and Lacroix (1997).
} 
provides a 'way around' which leaves the underlying economic model incomplete, but which allows for the estimation of the model parameters. Needless to say, the price that has to be paid for this is a loss in efficiency in the sense that the estimation result does not lead to the smallest parameter variance. The emphasis in our empirical approach is on obtaining estimates for the household's allocation process.

For reasons of comparison, we estimate different model specifications. We specify two restricted sharing rules, one of which imposes income pooling and two variants with a 'flexible' sharing rule that allow for additional effects of the wage rates and non-labour income on the sharing of income between partners. We evaluate the model on the basis of elasticities of labour supply, the implications for intrahousehold allocation, and the simulation of a policy change in the tax system. We use a dataset on childless couples from the Dutch Socio Economic Panel (SEP) for the years 1990-2001.

The results show that the model variants with a 'flexible' sharing rule have quite different outcomes for the allocation of income between household members, even if differences in wage elasticities of labour supply are not that outspoken. Income pooling fails because it is not able to capture asymmetries in the allocation of income between household members. Men, often the primary earner, transfer more of their earnings to their spouse than women, and the allocation of non-labour income goes in the same direction. This has implications for the effectiveness of tax policies, as for instance changes in tax allowances act as changes in households' non-labour incomes which affect the intrahousehold allocation of resources asymmetrically, while the same holds true for changes in marginal tax rates.

In section 2 we formulate the collective version of the discrete hours choice model. In section 3 we present the econometric specification of our model. We specify the utility function of husband and wife, the error structure, the sharing rule, and the wage distribution. In section 4 we briefly describe the Dutch income tax system. Section 5 provides descriptive statistics of the data. Section 6 contains the results. Section 7 concludes. 


\section{The model}

\subsection{The collective framework}

In this section we formulate the collective discrete choice model for working hours. By formulating a discrete choice model we follow the literature on labour supply and taxes in which the specification of discrete choice models for working hours is common practice nowadays. The ease of implementation of the discrete choice model to incorporate complex tax systems is the main reason for the fact that this model has been applied so widely.

Throughout we will consider a two-member household consisting of husband and wife. The consumption level and the working hours are denoted by $\left(C_{m}, h_{m}\right)$ for the husband and $\left(C_{f}, h_{f}\right)$ for the wife. Utility of each household member is defined over consumption and working hours, and is denoted by $U_{j}\left(C_{j}, h_{j}\right), j=m, f$. We assume that preferences are egoistic, and that there are no public goods in the household. ${ }^{11}$ We assume that individuals allocate their total time to leisure and paid work. ${ }^{12}$ The gross hourly wage rates of husband and wife, and the household's nonlabour income are denoted by $w_{m}, w_{f}$, and $y$ respectively. Individuals may choose their working hours out of the set $S \equiv\left\{h^{0}, h^{1}, \ldots, h^{H}\right\}{ }^{13}$ (with $\left.h^{0}=0, H \geq 1, h^{j}>h^{j-1}, j=1, \ldots, H\right)$. We assume that the tax system is known and that the after tax income is a function of the working hours and the gross hourly wage rates of husband and wife, and of the household's non-labour income. Therefore, we denote the after tax income of the household as $g\left(h_{m}, h_{f}, w_{m}, w_{f}, y\right)$.

Let $\bar{u}_{m}\left(w_{m}, w_{f}, y\right)$ denote the utility level that is at least available to the husband. This utility level can be interpreted as the outcome of some bargaining process that leads to Pareto efficient allocations. Note that we assume here that the gross wage rates and nonlabour income influence the bargaining process. More general specifications are possible. Now we may write the choice problem of the household members according to the collective model

11 Chiappori et al. (2005) relaxed the assumption of the absence of public goods. However, identification of the model parameters requires information of the households' expenditures on the public good.

12 Thus, we do not consider time that is spent on household production. Chiappori (1997) incorporates household production in the collective labour supply model. Unfortunately, time spent on household production by separate household members is not observed in our data.

${ }^{13}$ In section 4, in which we describe the data, we will be more specific about the hours values in the choice set. 
as follows: ${ }^{14}$

$$
\begin{gathered}
\max _{h_{m} \in S, h_{f} \in S, C_{m}, C_{f}} U_{f}\left(C_{f}, h_{f}\right) \\
U_{m}\left(C_{m}, h_{m}\right) \geq \bar{u}_{m}\left(w_{m}, w_{f}, y\right) \\
C_{m}+C_{f}=g\left(h_{m}, h_{f}, w_{m}, w_{f}, y\right) \\
S=\left\{h^{0}, \ldots, h^{H}\right\}
\end{gathered}
$$

Suppose that the tax system consists of several tax brackets, each of which has its own marginal tax rate. To keep notation as general as possible, we assume that the prevailing tax bracket is the result of the combination of gross hourly wage rates $\left(w_{m}\right.$ and $\left.w_{f}\right)$, working hours $\left(h_{m}\right.$ and $\left.h_{f}\right)$ of both partners, and the household's non-labour income $y,{ }^{15}$ and as such we denote the slopes $\omega_{m}$ and $\omega_{f}$ for husband and wife (obtained after applying the corresponding marginal tax rates to the gross hourly wage rates), and the intercept $\mu$ of the household budget constraint, as

$$
\omega_{j}=\omega_{j}\left(w_{m}, w_{f}, h_{m}, h_{f}, y\right), \mu=\mu\left(w_{m}, w_{f}, h_{m}, h_{f}, y\right), j=m, f
$$

To be precise, the slopes and intercept in (2) are defined by the parameters of the tax system: they are not a model assumption.

Thus, the household budget constraint can be represented by

$$
C_{m}+C_{f}=g\left(h_{m}, h_{f}, w_{m}, w_{f}, y\right)=\omega_{m} h_{m}+\omega_{f} h_{f}+\mu
$$

First, note how the choice of working hours by one partner affects the choice of the other. If the husband decides to choose a higher level of working hours, the total household budget changes and consequently the choice of working hours by the wife may be affected. Suppose that the husband's net labour income increases as the result of the increase in his working hours. Then the impact on the working hours of the wife depends on the allocation of this additional income to male and female consumption. If part of the additional income

\footnotetext{
14 The total time endowment was normalized to 1. There are alternative representations of the same maximization problem. By writing down the Lagrangian we may obtain the 'household welfare function' which is additive in the utility levels of both husband and wife.

${ }^{15}$ In practice tax systems can be of simpler nature. For instance, the prevailing tax bracket may depend on either joint or individual earnings of household members, but these specific cases fit in the general notation that we employ.
} 
is transferred to the wife and if the wife's leisure is a normal good, she may reduce her working hours. If, however, the additional income is spent entirely on the consumption of the husband, or if the consumption of the wife will be reduced, the wife's working hours may stay the same or increase. Consequently, the interaction of the working hours of husband and wife depends on the way husband and wife share the total household income, which depends both on their relative bargaining power and on their preferences. In the unitary model, the additional income raised by the increase in working hours would be pooled and added to the household income. ${ }^{16}$

\subsection{The sharing rule representation}

In this section we formulate the sharing rule representation of the decision problem (1). We first define this representation. Using the notation in (1), if the husband's working hours are equal to $h_{m} \in S$, then the husband's consumption level is implicitly defined by

$$
u_{m}\left(C_{m}, h_{m}\right)=\bar{u}_{m}\left(w_{m}, w_{f}, y\right)
$$

If $V_{m}\left(., h_{m}\right)$ is the inverse of the mapping $u_{m}\left(., h_{m}\right),{ }^{17}$ we may write

$$
C_{m}=V_{m}\left(\bar{u}_{m}\left(w_{m}, w_{f}, y\right), h_{m} ; w_{m}, w_{f}, h_{m}, h_{f}, y\right)=\psi\left(w_{m}, w_{f}, h_{m}, h_{f}, y\right)
$$

In (5) we also make explicit that $C_{m}$, by the nature of the tax system and the household budget constraint in (1), depends on $\left(w_{m}, w_{f}, h_{m}, h_{f}, y\right)$.

To express consumption in terms of virtual wage rates and virtual nonlabour income, we implicitly define a function $\rho\left(\omega_{m}, \omega_{f}, h_{m}, h_{f}, \mu\right)$ such that

$$
\omega_{m} h_{m}+\rho\left(\omega_{m}, \omega_{f}, h_{m}, h_{f}, \mu\right)=\psi\left(w_{m}, w_{f}, h_{m}, h_{f}, y\right)
$$

in which $\omega_{m}, \omega_{f}$ and $\mu$ are the virtual wage rates and nonlabour income defined earlier in

\footnotetext{
${ }^{16}$ A discrete choice set may impose additional restrictions on the household's income sharing rule. Blundell et al. (2007) formulate a collective model of household labour supply in which the wife can choose from a continuous range of working hours, but the husband's choice is restricted to choosing to work 40 hours a week or not to work at all, and show that Pareto efficiency of the underlying decision problem requires the 'double indifference' condition. However, if we consider our discrete choice set as an approximation for the continuous hours choice, discrete 'jumps' in income due to 'jumps' in working hours get smaller and smaller the more refined is the discretization of the hours choice set.

${ }^{17}$ Conform Blundell et al. (2007).
} 
(2). In defining $\rho$ in (6) we implicitly assumed that any effects of gross hourly wage rates $w_{m}$ and $w_{f}$ on sharing completely run via the slopes and intercepts of the budget constraint $\omega_{m}, \omega_{f}$ and $\mu$.

So far, we have done nothing else than reformulating the problem and redefining notation. The question, though, is whether a unique function $\rho\left(\omega_{m}, \omega_{f}, h_{m}, h_{f}, \mu\right)$ exists such that the collective discrete hours decision problem can be represented by two individual decision problems, conditional on the sharing rule. Partner $j$ in the household chooses his or her working hours by solving the following problem:

$$
\begin{gathered}
\max _{h_{j} \in S} u_{j}\left(C_{j}, h_{j}\right) \\
\text { subject to } C_{j}=\omega_{j} h_{j}+\rho_{j}\left(\omega_{m}, \omega_{f}, h_{m}, h_{f}, \mu\right) \\
\rho_{m}=\rho, \rho_{f}=\mu-\rho \\
j=m, f
\end{gathered}
$$

Donni (2003) extends the identification by Chiappori (1988) to the context of a piecewise non-linear but convex budget set due to taxation. If all regularity conditions are satisfied, the consumption levels are smooth functions of the spouse's working hours. ${ }^{18}$ If there are non-convexities in the budget set, smooth functions of virtual wage rates and non-labour incomes do not exist. This means that there can be discrete jumps in the consumption level if the spouse's working hours change. One approach is to comply with the theoretical results and 'convexify' the budget set, which means that non-convexities in the budget imposed by the tax system are ignored, and we abstain from specifications that allow for fixed costs of work. But such convexification would serious limit the applicability of the model in a world in which non-convex budget sets due to taxation are quite common, whereas the concept of fixed costs is in the empirical labour supply literature often used as an explanation for differences in the sensitivity of working hours to wage at the intensive and the extensive margin. Moreover, the empirical discrete hours choice model uses utility functions that are flexible and need not a priori satisfy all regularity conditions. This is often used as an argument in favour of this method.

\footnotetext{
18 The latter affect the consumption levels by the virtual wage rates and non-labour incomes.
} 
With the estimation strategy we follow, we try and address the following question: can we still proceed and estimate the parameters of preferences and the sharing rule without imposing a convex budget set? We will first show which are the consequences of ignoring the regularity condition of a convex budget set for the choice probabilities for working hours. In fact, the underlying economic model is incomplete. We can always define a function $\rho$ as in (6), and, conditional on female working hours $h_{f}$, the level of male working hours $h_{m}$ is uniquely defined. But that does not mean that there is a unique outcome of (7). We argue that there can be two pairs of working hours, say $\left(h_{m}^{k}, h_{f}^{l}\right)$ and $\left(h_{m}^{r}, h_{f}^{s}\right), r \neq k, s \neq l$, (with the superscripts indicating different discrete hours levels), that are both a solution to (7). Having multiple solutions is the result of the incompleteness of the economic model that does not provide a selection mechanism between the two outcomes. But for each couple, we

only observe one pair of hours, say $\left(h_{m}^{k}, h_{f}^{l}\right)$. The result of possibly having multiple solutions is that the choice probabilities, summed over all hours categories, need not add up to one. In statistical terminology, the model is incoherent. Maximum likelihood estimation based on these choice probabilities would lead to inconsistent estimates. However, given the spouse's working hours, the outcome of the model is unique for the individual. We will use this property in the estimation of the model, at the cost of losing efficiency of the estimator. In the next section we will explain this estimation strategy in detail.

\section{Econometric specification}

We first present the error structure and we formulate the choice probabilities of working hours. Next we discuss the coherency problem and the estimation strategy to overcome this. More details about the specification follow.

\subsection{The error structure}

Cf. Van Soest (1995) we add an error term, distributed according to the extreme value distribution, to the utility levels of each working hours level from the choice set. Suppose that the observed numbers of working hours of husband and wife are $h_{m}^{k}$ and $h_{f}^{l}$ respectively, 
with $k, l \in\{0, \ldots, H\}$. We denote the utility of husband and wife by

$$
\begin{gathered}
u_{m}\left(C_{m}^{k l}, h_{m}^{k}\right)=u_{m}^{k l}\left(\nu_{m}\right)+\epsilon_{m}^{k} \\
u_{f}\left(C_{f}^{l k}, h_{f}^{l}\right)=u_{f}^{l k}\left(\nu_{f}\right)+\epsilon_{f}^{l} \\
k, l \in\{0, \ldots, H\}
\end{gathered}
$$

The superscripts $k l$ and $l k$ denote that the values of the utility levels depend on $h_{m}^{k}$ and $h_{f}^{l}$, whereas $\nu_{m}$ and $\nu_{f}$ represent unobserved heterogeneity affecting preferences but not specific to the hours category chosen. For the additive error terms $\epsilon_{m}^{k}$ and $\epsilon_{f}^{l}$ we make the following assumptions: (i) $\epsilon_{j}^{r}, j=m, f, r=0, \ldots, H$, are independently and identically distributed according to the extreme value distribution; (ii) $E\left(\epsilon_{j}^{r} \mid h_{m}, h_{f}, w_{m}, w_{f}, y, \nu_{j}\right)=0, j=m, f, r=$ $0, \ldots, H$.

The combination of working hours $h_{m}^{k}$ and $h_{f}^{l}$ is observed if two conditions are met simultaneously. For the wife, we have

$$
u_{f}^{l k}\left(\nu_{f}\right)+\epsilon_{f}^{l}>u_{f}^{s k}\left(\nu_{f}\right)+\epsilon_{f}^{s}, s \neq l, s=0, \ldots, H
$$

whereas for the husband

$$
u_{m}^{k l}\left(\nu_{m}\right)+\epsilon_{m}^{k}>u_{m}^{r l}\left(\nu_{m}\right)+\epsilon_{m}^{r}, r \neq k, r=0, \ldots, H
$$

The parameters entering the wife's utility $u_{f}^{l k}\left(\nu_{f}\right)$ can be estimated by formulating the probability that (9) occurs and applying maximum likelihood estimation. Denoting this probability by $p_{f}^{l k}\left(\nu_{f}\right)$ we get

$$
p_{f}^{l k}\left(\nu_{f}\right)=\frac{\exp \left(u_{f}^{l k}\left(\nu_{f}\right)\right)}{\sum_{s=1}^{H} \exp \left(u_{f}^{s k}\left(\nu_{f}\right)\right)}, l=0, \ldots, H
$$

The probabilities add up to 1 over hours levels $l=0, \ldots, H$. Integration over the unobserved heterogeneity $\nu_{f}$ determines the final expression for the probability. Similarly, we can estimate the parameters entering (10) based on the probabilities

$$
p_{m}^{k l}\left(\nu_{m}\right)=\frac{\exp \left(u_{m}^{k l}\left(\nu_{m}\right)\right)}{\sum_{r=1}^{H} \exp \left(u_{m}^{r l}\left(\nu_{m}\right)\right)}, k=0, \ldots, H
$$

Also the probabilities (12) add up to 1 over the hours categories $k=0, \ldots, H$, and we will integrate over the unobserved heterogeneity $\nu_{m}$. Thus, maximum likelihood estimation can 
always be based on the probabilities (12) and (11).

However, can we improve efficiency of the estimator by efficiency by formulating the joint probability $p_{m f}^{k l}\left(\mu_{m}, \nu_{f}\right)$ that (9) and (10) are satisfied simultaneously,

$$
p_{m f}^{k l}\left(\mu_{m}, \nu_{f}\right)=p_{m}^{k l}\left(\nu_{m}\right) p_{f}^{l k}\left(\nu_{f}\right), k, l=0, \ldots, H
$$

Now integration over $\nu_{m}$ and $\nu_{f}$ involves the joint distribution $g\left(\nu_{m}, \nu_{f}\right)$ of $\left(\nu_{m}, \nu_{f}\right)$, unlike in the separate expressions (11) and (12), which involve the integration over the marginal distributions only:

$$
p_{m f}^{k l}=\iint p_{m f}^{k l}\left(\nu_{m}, \nu_{f}\right) g\left(\nu_{m}, \nu_{f}\right) d \nu_{m} d \nu_{f}, k, l=0, \ldots, H
$$

\subsection{Coherency problem and estimation strategy}

To perform maximum likelihood estimation based on the joint probability (14), the outcome of (9) and (10) needs to be unique. By uniqueness we mean that for given values of $\epsilon_{f}^{s}, s=0, \ldots, H$ and $\epsilon_{m}^{r}, r=0, \ldots, H$ the observed hours combination $\left(h_{m}^{k}, h_{f}^{l}\right)$ is the unique combination of male and female working hours that satisfies (9) and (10) simultaneously. In other words, there is no other pair of working hours $\left(h_{m}^{r}, h_{f}^{s}\right), r \neq k, s \neq l$ which also satisfies (9) and (10) simultaneously for the same values of the errors.

To explain this issue further, let us consider (9). First note that if the condition (9) for the choice of female working hours is satisfied for a given level of male working hours $h_{m}^{k}$, for certain values of $\epsilon_{f}^{s}, s=0, \ldots, H$, the outcome of female working hours $h_{f}^{l}$ is unique. Now the question is how the optimal choice of the female's working hours depends on the male

level of working hours. Is the outcome $h_{f}^{l}$ still optimal, for a different value of the hours of the husband, say $h_{m}^{j}, j \neq k$, at the same values of $\epsilon_{f}^{s}, s=0, \ldots, H$ ? The answer depends on how the hours level of the husband affects the utility level of the wife. From the decision problem (7) we see that the hours level of the husband affects the wife's utility level not by preferences, but by the sharing rule and, possibly, by the tax system (conform (2)). If the utility of the wife is monotonous in the hours of the husband, we have a sufficient condition for the uniqueness of the hours level $h_{f}^{l}$ for all possible hours level of the husband, at given values of $\epsilon_{f}^{s}, s=0, \ldots, H$. 
But even if at hours $h_{m}^{j}, j \neq k$ and values of $\epsilon_{f}^{s}, s=0, \ldots, H$, hours $h_{f}^{s}, s \neq l$ are optimal for the wife, the outcome of (9) and (10) is not necessarily unique. We also need that at given values $\epsilon_{m}^{r}, r=0, \ldots, H$ for which (10) is satisfied, (that is, $h_{m}^{k}$ is optimal at $h_{f}^{l}$ ) $h_{m}^{j}, j \neq k$ is optimal at $h_{f}^{s}, s \neq l$, for the same $j$ and $s$ as above. Again, uniqueness of the outcome $h_{m}^{k}$ for arbitrary values of the wife's hours depends on how the wife's hours influence the husband's decision problem, as described in (7). From (7) we see that the wife's hours possibly influence the husband's utility by the virtual wage rates, and the virtual non-labour income. So it depends on the properties of the tax system and the shape of the sharing rule whether the outcome of (10) and (9) will be unique.

Now we could formulate sufficient conditions for the uniqueness of a solution, like having a utility level that is monotonously increasing in consumption, with a convex tax system, but empirically we may not want to impose these restrictions a priori. A consequence of possibly having multiple solutions is that the joint probabilities in (13) and (14) may add up to an amount larger than 1 (added up over male hours, $k=0, \ldots, H$, and female hours $l=0, \ldots, H$ ). As a result, we cannot use the joint probability in the estimation of the model: applying maximum likelihood will bias outcomes in the direction of the regime where probabilities add up to values larger than one. However, we can use the probabilities for the separate conditions (12) and (11). This will come at the cost of losing efficiency in the estimation. For instance, using the separate conditions (12) and (11) precludes the estimation of a correlation between the unobserved heterogeneity $\nu_{m}$ and $\nu_{f}$ of men and women (as in (14)).

\subsection{The utility function}

We represent preferences by the following quadratic direct utility function: ${ }^{19}$

$$
\begin{aligned}
& u_{j}^{k l}=\left(\beta_{0, h h}^{j}+\beta_{h h}^{j} \prime z_{j}\right)\left(\ln \left(T-h_{j}^{k}\right)\right)^{2}+\beta_{c h}^{j} \ln \left(T-h_{j}^{k}\right) C_{j}^{k l}+\beta_{c}^{j} C_{j}^{k l}+ \\
& +\beta_{c c}^{j}\left(C_{j}^{k l}\right)^{2}+\left(\beta_{0 h}^{j}+\beta_{h}^{j} / z_{j}+\nu_{j}\right) \ln \left(T-h_{j}^{k}\right), j=m, f
\end{aligned}
$$

\footnotetext{
${ }^{19}$ Van Soest (1995) specifies a discrete utility function that is log-quadratic in its arguments. However, in our model, based on the collective approach, the consumption level of a household member is equal to his or her earnings plus the share of non-labour income, determined by the sharing rule. The intercept of the sharing rule is (non-parametrically) not identified, since the only restriction imposed is adding-up across household members. Consequently, the sharing rule need not be positive. Therefore we include consumption in levels.
} 
In $(15) z_{j}$ represents a vector of observable taste shifters that may influence the preferences for leisure, ${ }^{20}$ whereas $\beta_{0, h h}^{j}, \beta_{h h}^{j}, \beta_{\nu}^{j}, \beta_{c h}^{j}, \beta_{c}^{j}, \beta_{c c}^{j}, \beta_{0, h}^{j}$ and $\beta_{h}^{j}$ are the parameters of the utility function. $T$ is the total time endowment. It is set to 168 hours a week in the empirical application. The utility function of spouse $j$ contains an unobserved taste shifter $\nu_{j}$, and we assume that it is normally distributed:

$$
\left(\begin{array}{c}
\nu_{m} \\
\nu_{f}
\end{array}\right) \sim N\left(\left(\begin{array}{l}
0 \\
0
\end{array}\right),\left(\begin{array}{cc}
\sigma_{\nu, m}^{2} & --- \\
--- & \sigma_{\nu, f}^{2}
\end{array}\right)\right)
$$

A consequence of the estimation strategy that is followed to deal with the coherency issue is that the covariance between the unobserved heterogeneity of the two spouses cannot be estimated, and for this reason is indicated by - - - in the covariance matrix. We denote the density function of random preferences by $g\left(\nu_{m}, \nu_{f} ; \Sigma_{\nu}\right)$, where $\Sigma_{\nu}$ represents the covariance matrix.

It is straightforward to show that the utility function (15) is increasing in consumption if and only if

$$
M U_{C_{j}}=\beta_{c h}^{j} \ln \left(T-h_{j}^{k}\right)+\beta_{c}^{j}+2 \beta_{c c} C_{j}^{k l}>0, j=m, f
$$

In the estimation, (17) is not a priori imposed. Welfare levels are difficult to interpret if (17) is not satisfied.

Utility is increasing in leisure $l=T-h$ if

$$
2\left(\beta_{0, h h}^{j}+\beta_{h h^{j}}^{j} z_{j}\right) \ln \left(T-h_{j}^{k}\right)+\beta_{c h}^{j} g\left(C_{j}^{k l}\right)+\left(\beta_{0 h}^{j}+\beta_{h}^{j} z_{j}+\nu_{j}\right)>0, j=m, f
$$

Quasi-concavity is satisfied if

$$
-\frac{1}{U_{c}^{j}}\left(\begin{array}{ll}
-\frac{U_{l}^{j}}{U_{c}^{j}} & 1
\end{array}\right) H U^{j}\left(\begin{array}{ll}
-\frac{U_{l}^{j}}{U_{c}^{j}} & 1
\end{array}\right)^{\prime}>0, j=m, f
$$

with $U_{c}^{j}$ and $U_{l}^{j}$ the partial derivative of utility with respect to consumption and leisure, and $H U^{j}$ the hessian of the utility function with respect to consumption and leisure.

\footnotetext{
${ }^{20}$ We could have made the utility specification even more flexible, by making the parameters of consumption, $\beta_{c}^{j}$ and $\beta_{c c}^{j}$ a function of the taste shifters $z_{j}$. But in the present specification, the marginal rate of substitution between consumption and leisure already is a function of the taste shifters $z_{j}$ and also making $\beta_{c}^{j}$ and $\beta_{c c}^{j}$ a function of the taste shifters $z_{j}$ a function of taste shifters would make both the numerator and the denominator of the marginal rate of substitution a function of the taste shifters, which looks like overparameterizing the model.
} 


\subsection{Specification of the sharing rule}

In (6) the sharing rule $\rho$ was defined as a function of the (virtual) wage rates of husband and wife, the (virtual) nonlabour income of the household, and of the working hours of both spouses. ${ }^{21}$ Accordingly, we specify the following sharing rule: ${ }^{22}$

$$
\begin{aligned}
& \rho\left(\omega_{m}, \omega_{f}, h_{m}, h_{f}, \mu\right)= \\
& \alpha_{0}+\alpha_{1} w_{m}+\alpha_{2} w_{f}+\alpha_{3} \mu+\alpha_{4} D+\alpha_{5} h_{m}+\alpha_{6} h_{f}+\alpha_{7} \mu^{2}
\end{aligned}
$$

In (20) $D$ is a factor that represents the relative bargaining power of husband and wife. Economic theory does not provide strong guidelines for parameterizing a bargaining measure, and therefore we estimate the model with two different specifications. First, we choose $D$ as the husband's virtual wage rate expressed as the share of the sum of husband's and wife's virtual wage rates:

$$
D=\frac{\omega_{m}}{\omega_{m}+\omega_{f}}
$$

A second variant is based on net earnings instead:

$$
D=\frac{E_{m}}{E_{m}+E_{f}}
$$

with $^{23}$

$$
E_{j}=\omega_{j} h_{j} \text { if } h_{j} \in\left\{h^{1}, \ldots, h^{H}\right\}>0 \text { and } E_{j}=\omega_{j} \text { if } h_{j}=0, k=m, f
$$

Recall that $\rho=\rho_{m}$, the husband's share, while the wife's share follows from (20) as $\rho_{f}=$ $\mu-\rho_{m}$. Moreover, by the budget constraint, $C_{j}=\omega_{j} h_{j}+\rho_{j}, j=m, f$.

Apart from estimating model variants with sharing rule specification (20) with two different definitions for $D$, we estimate two alternative specifications with a restrictive sharing rule. In the first we assume that half of the household's virtual non-labour income is assigned

\footnotetext{
21 The latter follows from the discrete choice nature of the model specification. In continuous hours specifications the sharing rule would never depend on working hours. In their model of restricted choice by the husband, Blundell et al. (2007) actually specify two separate sharing rules for the two choice opportunities (0 or 40 hours) of the husband.

${ }^{22}$ In the empirical application we will allow the parameters of the sharing rule to be different by marital status.

${ }^{23}$ At zero hours, $E_{j}$ represents the marginal earnings capacity of working 1 hour.
} 
to each partner:

$$
\rho_{\text {half }}\left(\omega_{m}, \omega_{f}, h_{m}, h_{f}, \mu\right)=\frac{1}{2} \mu
$$

This rule is almost equivalent to assuming that each household member consumes his or her own earnings and only the virtual non-labour income is split. The next variant is equivalent to income pooling: household members base their decision on total household income. The corresponding sharing rule is

$$
\rho_{\text {pool }}\left(\omega_{m}, \omega_{f}, h_{m}, h_{f}, \mu\right)=-\frac{1}{2} \omega_{m} h_{m}+\frac{1}{2} \omega_{f} h_{f}-\frac{1}{2} \mu
$$

Formally, the sharing mechanism (25) implies that the husband transfers half of his net earnings to the wife, while the wife transfers half of her net earnings to the husband, and virtual non-labour income is split equally. This leads to consumption levels $C_{m}=C_{f}=$ $\left(\omega_{m} h_{m}+\omega_{f} h_{f}+\mu\right) / 2$. When implemented in a model with utility specification (15) this is equivalent to basing individual labour supply choices on pooled household income.

In the estimation of the model data for several years are used. Throughout we assume that the parameters of the sharing rule $\alpha_{j}$ remain constant across time. Thus, we implicitly assume that there is no renegotiation on the shape of the sharing rule if the value of any of the variables entering the sharing rule changes over time. In other words, the marginal effects of the variables affecting the share remain constant. Only changes across time in the levels of the variables affect the allocation of income between household members.

\subsection{Identification}

Constructing the consumption levels $C_{j}=\omega_{j} h_{j}+\rho_{j}, j=m, f$ using the sharing rule (20) imposes parameter restrictions between the consumption levels of husband and wife. These parameter restrictions arise due to the adding up condition $\rho_{f}=\mu-\rho_{m}$. To make these

restrictions explicit, we specify the 'reduced form' consumption functions $C_{m}^{*}$ and $C_{f}^{*}$ for husband and wife:

$$
C_{m}^{*}=\omega_{m} h_{m}+\gamma_{1}^{m} \omega_{m}+\gamma_{2}^{m} \omega_{f}+\gamma_{3}^{m} \mu+\gamma_{4}^{m} D+\gamma_{5}^{m} h_{m}+\gamma_{6}^{m} h_{f}+\gamma_{7}^{m} \mu^{2}
$$


and

$$
C_{f}^{*}=\omega_{f} h_{f}+\gamma_{1}^{f} \omega_{m}+\gamma_{2}^{f} \omega_{f}+\gamma_{3}^{f} \mu+\gamma_{4}^{f} D+\gamma_{5}^{f} h_{m}+\gamma_{6}^{f} h_{f}+\gamma_{7}^{f} \mu^{2}
$$

Before continuing, we would like to emphasize that the purpose of this section is to shed light on the identification, and not to set up a specification for the purpose of estimation. The reduced form specifications contain too many parameters and yield, in practice, an overparameterized model with flat likelihood functions. We will therefore not test the restrictions.

Inserting (26) and (27) into (15) (for $j=m, f$ ) reveals more about the identification of both the preference parameters and the parameters $\gamma_{l}^{j}$ of the reduced form consumption. First, the preference parameters $\beta_{c}^{j}, \beta_{c c}^{j}$, and $\beta_{c h}^{j}, j=m, f$ are identified because they measure the impact of earnings $\omega_{j} h_{j}, j=m, f$, earnings quadratic, and the cross effect of earnings with working hours on the hours choice probabilities. In this respect, the model is not different from the standard, unitary, discrete choice labour supply model. Second, every variable included in the sharing rule that is also included in the vector of taste shifters cannot be identified. This corresponds to the standard result by Chiappori (1988) that the sharing rule can be identified up to an additive constant. Therefore, we ignore the intercept $\alpha_{0}$ in (20). For the remaining, none of the variables included in (20) are typical taste shifters. Third, note that $h_{m}$ in (26) and $h_{f}$ in (27) are transformations of log-leisure entering the utility functions (15). Therefore, $\gamma_{5}^{m}$ and $\gamma_{6}^{f}$ are not identified non-parametrically, but once the adding-up constraint of the utility maximization problem (7) is imposed we learn that $\gamma_{5}^{m}=-\gamma_{5}^{f}$ and $\gamma_{6}^{f}=-\gamma_{6}^{m}$, by which identification is achieved.

In general, we can formulate the parameter restrictions resulting from the adding-up constraint as

$$
\begin{aligned}
& \gamma_{j}^{m}=-\gamma_{j}^{f}, j=1,2,4,5,6,7 \\
& \gamma_{3}^{m}=1-\gamma_{3}^{f}
\end{aligned}
$$

If we express the structural sharing rule parameters $\alpha_{l}$ as

$$
\alpha_{l}=-\gamma_{l}^{f}, l=1,2,4,6,7, \alpha_{3}=1-\gamma_{3}^{f}, \alpha_{5}=\gamma_{5}^{m}
$$

then (28) and (29) together show that we have 14 reduced form parameters from which we can uniquely solve the seven sharing rule parameters $\alpha_{l}, l=1, \ldots, 7$ since we have 7 cross 
equations constraints on the reduced form parameters.

\subsection{Fixed costs of work}

Previous studies that use the discrete hours framework reveal that the discrete choice model, once the parameters have been estimated, typically fails to predict the sample fraction of nonworking individuals (see Van Soest, 1995, and the remarks in Beninger and Laisney, 2002). This led to the practice of introducing fixed costs of work (see, for instance, Van Soest and Das, 2001). Fixed costs of work are not directly observed, but parameterized by allowing for a fixed discrete difference in the consumption level between labour market states. ${ }^{24}$ Suppose that the fixed cost of work of household member $j(j=m, f)$ is $F_{j}$. To introduce fixed costs we will assume that the income available for consumption is $C_{j}=\omega_{j} h_{j}+\rho_{j}-F_{j} \iota\left(h_{j}>\right.$ $0), j=m, f$. Note that we assign the fixed cost of household member $j$ completely to the consumption of household member $j$ and not to the partner. This is motivated by the double indifference condition (Blundell et al. 2007), which implies that the sharing rule should be a continuous function of the amounts of fixed costs of both partners (i.e. the amounts should enter the sharing rule for both working and non-working individuals). But if the amounts are fixed, and if there are no variables that affect fixed costs of work and not the marginal utility of working hours we cannot identify fixed costs of work from the sharing rule, as the sharing rule is identified up to an additive constant only. Therefore, the fixed costs of work only enter the individual consumption levels.

\section{The income tax system in the Netherlands}

Our data provide information for the years 1990-2001. Throughout the years 1990-2000 there are year to year differences in marginal tax rates and general tax credits, but no major changes in the Dutch income tax system occurred. In the Dutch tax system individual incomes are taxed. Every individual has a general (applicable, irrespective of the individual characteristics) tax credit: ${ }^{25}$ the marginal tax rate for any income below this amount is zero.

\footnotetext{
${ }^{24}$ We have already discussed the problems with nonconvex budget sets and fixed costs lead to a nonconvexity in the budget set.

25 The Dutch terminology in the law is the 'basisaftrek'.
} 
There is some relationship between the income taxation of two partners in a household. Only if a household member earns an income that is below the general tax credit, s/he can transfer the tax credit to her/his partner. This raises household income if the partner earns more than the tax credit. Transferring the tax credit to the higher income partner, if the household is eligible for it, is the standard practice among households in the Netherlands. In the years 1998 through 2000 the tax credit was split up into a small non-transferable amount $^{26}$ and the transferable amount. In 1990 through 1998 there were three tax brackets for the income net of the general tax credit. ${ }^{27}$ In 1999 a fourth income tax bracket was introduced. The marginal tax rate for the first bracket varies from year to year, because it partly consists of premiums for social welfare. The marginal tax rate for the two higher brackets remained at 50\% and 60\% throughout the years, except for 2001, for which the values are $42 \%$ and $52 \%$. Table 1 shows the tax credits throughout the years 1990-2001. ${ }^{28}$

\section{The data}

The SEP is a household survey collected by Statistics Netherlands. We use data from the Socio-Economic Panel (SEP) for the years 1990 to 2002. During this period, Statistics Netherlands interviewed households on a yearly basis, every May. The income in a given survey wave refers to the previous calendar year: the income information in the survey is based on the income information that individuals provided to the tax administration for determining income taxes for the previous year, which typically has to be finished and returned to the tax authorities by April. For this reason, we link data from two subsequent waves to get the complete information for one year. Consequently, for each individual we

\footnotetext{
${ }^{26}$ The so called 'bovenbasisaftrek'.

27 The 'belastbare som'.

${ }^{28}$ As an example, consider the year 1997 and suppose that the wife earns less than 7102 guilders a year. (The actual tax credit can never exceed the value of her income). Then she may transfer the full tax credit of 7102 to her husband. She will then have a tax credit of zero, whereas the tax credit for her husband will be 14204 guilders. The advantage for the household income as a whole is (i) that the complete tax credit of 7102 is exploited. (For instance, if the wife's income is 6000 guilders, her tax credit is only 6000) and (ii) if the husband is in the second or third tax bracket there is an additional gain since at the margin the husband's income is taxed at a higher rate than the wife's income as the tax system is progressive. Van Soest and Das (2001) plotted the impact of transferring the deductible to the other partner on the budget constraint for the year 1998. The shape of the budget constraint shows a nonconvex kink at low numbers of working hours, but the nonconvexity is rather small.
} 
have information for the years 1990 through 2001.

For each year, we selected couples living together (either married or unmarried) without children, in which the male is in the age range of 22 to 60 and the female is no older than 60. ${ }^{29}$ We excluded households in which either husband or wife reports to be self-employed. Furthermore, we require the availability of information on the labour market state of both household members, the non-labour income, and information on the level of schooling and the sector of education. We use information on hourly wage rates and employment status for the estimation of the wage equation. The pooled dataset contains 8049 observations (in which the observation unit is the two-member household).

Table 2 contains descriptive statistics for the pooled data. Note that $86.3 \%$ of the male respondents is employed and $72.5 \%$ of their female partners. In interpreting these numbers we should recall that we selected couples without children. Therefore, the percentage of working females is relatively high in our sample. At the household level we see that in $66.9 \%$ of the households both spouses are working and in $19.5 \%$ of the households the husband works, while the wife does not. For $8.1 \%$ of the households none of the members is working, whereas in only $5.6 \%$ of the households only the wife works.

Note that on average the males in the sample are higher educated than the females. We have also information about the direction, or sector, of education and here we see some typical differences between males and females. There are few women with a technical type of education whereas the majority of the men was trained for technical professions. The majority of women is educated for the service sector. There are also more women without specialization in education. The mean age for males is about 2 years higher than for females.

Mean weekly working hours for males are about 40, whereas females work 31 hours a week on average. The male hourly wage rate is more than 2 guilders higher than the wage rate of females. The non-labour income includes interest income, income out of real estate, rent subsidy, income out of life insurance, ${ }^{30}$ gifts by family, dividend income and income out of profits and scholarships. In the survey it is measured on a yearly basis and in Table 1 it is converted to guilders per week. The average is about 37 guilders a week, and there is

\footnotetext{
${ }^{29}$ The age of 60 was the most common age for eligibility to early retirement benefits in the Netherlands. 30 'Lijfrente'.
} 
quite some variation in it, with some households reporting much higher amounts, and some households reporting not to have received any non-labour income.

Our point of departure was to classify working hours into intervals of 6 hours, and such that the most prevailing working hours levels have a separate category. ${ }^{31}$ However, we imposed restrictions because sample frequencies of men working less than 2 days a week were quite low. ${ }^{32}$ In addition, there are hardly any women working more than 40 hours a week. We therefore have a somewhat different classification for men and women. Zero working hours is treated as a separate class. If $h_{m}^{k}$ denotes the classified hours value for men and $h$ is the observed value, then we classify $h$ (for men) as follows:

$$
\begin{aligned}
& h_{m}^{0}=0 \text { if } h=0 \\
& h_{m}^{1}=9 \text { if } 0<h<=18 \\
& h_{m}^{k}=6(k+2)-3 \text { if } 6(k+1)<h \leq 6(k+2), k=2, \ldots, 7 \\
& h_{m}^{8}=57 \text { if } h>54
\end{aligned}
$$

For women, we have

$$
\begin{aligned}
& h_{f}^{0}=0 \text { if } h=0 \\
& h_{f}^{k}=6 k-3 \text { if } 6(k-1)<h \leq 6 k, k=1, \ldots, 8 \\
& h_{f}^{9}=51 \text { if } h>48
\end{aligned}
$$

\section{Estimation results}

As a first step, we estimated parameters of selectivity corrected wage equations (see Appendix A, the estimates in the tables A.1 and A.2). Next, to estimate the parameters of the labour supply model by (simulated) maximum likelihood, we use 25 Halton draws to simulate gross wage rates $^{33}$ and unobserved heterogeneity and average the hours choice probabilities in (12)

\footnotetext{
${ }^{31}$ For instance, part-time jobs of 20 hours a week and 24 hours a week (3 days) are included in a separate category $k=4$, so are jobs of 4 working days a week are included and full-time jobs of 38-40 hours a week.

32 There is a positive frequency in each 6 hours category, but in combination with the female hours classes we ended up with some empty combinations of male and female working hours.

33 Halton draws are generally known to perform well, even with a low number of replications. We use simulated wages for both the nonemployed and the employed in the sample. By using simulated wage rates, rather than expected wage rates, we aim to incorporate the impact of wage dispersion in this non-linear
} 
and (11), following the procedure outlined in section 3.

We present the estimation results of four model variants. We have the simplified sharing mechanisms (24) and (25), the latter of which represents income pooling, and the flexible sharing rule (20) with two different definitions of relative income of the partners, one based on virtual wage rates (21) and the other on net earnings (22).

Table 3 contains the base parameters of the utility function for each specification, and Table 4 shows the parameters of the sharing rule (for the model variants with the flexible sharing rule). The parameter estimates of all the taste shifters and fixed costs are presented in Appendix B, Tables B1 through B3.

Most of the parameters are not directly interpretable in isolation, so we use different ways to evaluate the estimation results obtained with the different model variants. In the evaluation we place the emphasis on the behavioural outcomes of the model variants. Presenting the wage elasticities of working hours and participation is an obvious way to see whether different model variants imply different outcomes. The collective model allows for the analysis of the intrahousehold allocation of income. We will evaluate how this allocation changes as a response to changes in husband's and wife's (gross) wage rates. We simulate a change in the tax system that is similar to the actual policy change that took place in the Netherlands in the year 2001. We will evaluate how this affects the income sharing between husband and wife.

The order of the presentation of results is as follows. In sections 6.1 we will briefly discuss the parameter estimates themselves. Section 6.2 presents wage elasticities of labour supply. In section 6.3 we discuss marginal effects of husband's and wife's wage rates on the allocation of income. Section 6.4 presents results of the simulation of the 2001 tax reform.

\subsection{Parameter estimates: preferences and the sharing rule}

The preference parameters in Table 3 determine whether positive marginal utility of consumption (17) is satisfied. We verified condition (17) globally, that is for all hours combinations $k$ and $l$, and for each of the 25 simulated wage rates of both partners used in

model. In a previous version of this study, we only used predicted wages, thereby ignoring the dispersion of wages. 
the estimation. Table 3 shows that positive marginal utility of consumption is satisfied for all men in the sample for all the model specifications, and for around $98 \%$ of the women. Given the global nature of our check and the small percentage that does not satisfy positive marginal utility for all variants, we do not undertake additional action to impose positive marginal utility of consumption in one way or another.

Table 4 shows the parameter estimates of the sharing rule. Since the parameters represent marginal effects of virtual wage rates, hours, a relative income measure, and virtual nonlabour income, the parameters are not interpretable in isolation, and in section 6.3 we will therefore discuss results of changes in gross wage rates on the share and consumption of each spouse.

A first observation that we can make from Table 4 is that the wage effect of men on their share is negative, indicating that husbands transfer funds to their wives upon an increase in their wages. We also see that for the variant with the definition of $D$ as in (21), based on the relative virtual wage rate, there is an opposing positive effect through the variable $D$, indicating that the virtual wage rate of the husband relative to that of the wife matters. In variant with $D$ defined by relative earnings, as in $(22)$, such a relative effect seems to be largely absent.

\subsection{Elasticities}

To evaluate whether different model specifications generate different outcomes, wage elasticities of working hours were computed. To this purpose, a simulation was run that increased the gross wage rates of, subsequently, men and women, by $1 \%$. Working hours of men and women were simulated from their joint distribution (14) before and after the simulated wage increase. ${ }^{34}$ A similar simulation was run for non-labour income. Table 5 displays the elasticities of both working hours (including zeros) and participation.

For all variants the largest elasticities are the female own wage elasticities for participation and working hours, which are significantly positive in all cases. The wife's own wage effects are bigger for the restricted sharing rule (24). This sharing mechanism allocates own wage

\footnotetext{
${ }^{34}$ Adding up to one was imposed by normalizing the probabilities by the sum of the probabilities over all hours categories.
} 
incomes largely to the own consumption, while non-labour income is shared equally. This may explain why the wife's own elasticity is bigger in this case. It is interesting to see that the elasticity under sharing rule (25), which exhibits income pooling, is virtually equal to the flexible sharing mechanisms (20). So for the estimation of the wife's own wage elasticities, income pooling does not seem to impose heavy restrictions. However, we should note that all the cross wage elasticities are small in magnitude, so this result may not carry over to situations where cross wage effects have more weight. For the flexible sharing rule, we see some evidence of a negative cross wage effect of male wage rates on female participation. ${ }^{35}$

\subsection{Intrahousehold allocation}

The implementation of a collective labour supply model provides the opportunity to gain insight in the intrahousehold allocation mechanism. To make the models' implications for income allocation visible, Table 6 records who gains by an increase of, subsequently, the gross wage rate of the husband, the gross wage rate of the wife, and the household's nonlabour income. Table 6 shows the percentage of husbands and wives with increases in consumption and in the share (set by the sharing rule) as a result of these increases in income components. Table 6a records the results for the specifications with the restricted sharing rules, while Table $6 \mathrm{~b}$ shows the results with the flexible sharing rules. To obtain the results of a $1 \%$ increase in the gross wage of, say, the husband, wages were drawn and increased by $1 \%$. We simulated the joint labour supply of husband and wife before and after this wage increase. Thus, the outcomes include both marginal effects, as for instance measured by the parameters of the sharing rule, and the eventual behavioural changes in the working hours and participation.

Table 6a shows that the allocation mechanism for sharing rule (24) is very much set by the restrictive nature of the specific sharing rule. According to this rule, individual consumption levels are set to individual earnings plus half of the household's non-labour income. Accordingly, Table 6 a shows that the increase in the wage rate is largely allocated to the individual that experiences the wage increase and is participating (for non-participating

\footnotetext{
35 In a model with continuous hours, no fixed costs, a linear budget set, and net wage rates Bloemen (2010) finds elasticities that are somewhat bigger in magnitude, as may be expected for the given differences in wage measures and model specification.
} 
individuals with zero working hours a wage increase does have no impact on earnings), or is changing labour force status. A change in non-labour income, which is shared across household members, increases both partners' shares and consumption levels. Differences between married and unmarried women mainly come from their difference in labour market participation.

The results with sharing rule (25), which imposes income pooling, show that both partners benefit from the increase in the wage rate of one partner (Table 6a, bottom pane), since the person with the increase in earnings transfers half of it to his or her spouse. Behavioural changes in labour supply and participation do not change this pattern much. Both partners benefit from an increase in the non-labour income.

Tables 6 b shows the results for the flexible sharing rule (20) with the different definitions of the wage fraction $D$, as in (21) and (22). For both definitions of the sharing rule, an increase in the husband's wage rate mostly increases the share of the wife and her consumption, while a much smaller part of the husbands benefit from their own wage increase. This suggests that the husband transfers income to his wife. Transfers to the wife occur most often for the sharing rule with the relative income measure $D$ based on virtual wage rates, rather than on earnings.

Also for both specifications, an increase in the wife's wage rate increases the the consumption of both husband and wife. For husbands, this increase comes from the increased share of the husband. The interpretation could be that the husband, who is usually the primary earner in the household, reduces income transfers to the wife once her own individual wage rate rises.

There are some differences between the two specifications. For specification (22) mainly the participating women gain from the increase in income (as seen by the percentages). For this reason unmarried women gain more. Nevertheless we see an increase in the share for the largest part of the men, so also for the men with a non-participating wife. This somehow suggests that if a woman does not decide to work, in spite of better wage prospects, she loses in terms of intrahousehold income allocation. For the specification with (21) also nonworking women gain. In Table 4 we saw that the relative income measure for this specification matters, so bargaining power effects in favour of the woman are at work here. 
Both specifications have in common that an increase in non-labour income is mainly attributed to the wife. Results like this have implications for policy since something like a a general tax credit operates like a shift in non-labour income.

The results show very well why the restricted variants fail. First, we see that each partner shares at least part of his or her wage increase with the other partner, which contradicts the restricted specification $\rho_{\text {half }}$ in (24). The clear rejection of income pooling is shown by the asymmetry of an increase in the household's non-labour income, from which largely the wife benefits in terms of income sharing, and also the asymmetry of an increase in the husband's wage rate, who apparently transfers a large part of his wage increase to his wife.

\subsection{Simulating the tax reform}

To show the implications of using different specifications for policy change predictions, the effects of a counterfactual policy change in the tax system were simulated. First, the tax system of the year 2000 was applied to every observation in the sample and the working hours of husband and wife were generated from its joint distribution. Next, the simulation was repeated, but now with the tax rules of the year 2001. The policy change in 2001 was described in Section 4. According to this policy change, marginal tax rates stayed the same for the lower brackets but decreased for the higher, tax allowances partly became labour market state specific to stimulate participation, in total tax allowances became smaller, opportunities to transfer deductibles to the higher income partner were abolished, and the bounds of tax brackets changed. Without change in behaviour, some families with at least one non-working spouse are faced by decreased net incomes, while some workers may benefit from a lower marginal tax rate, either by an actual decrease in it, or by an extension of the tax bracket.

A priori it is expected that this policy change stimulates participation, notably for women. The collective model specifications can shed light on the implications of the policy change for the income sharing within households.

Table 7 shows the outcomes of the simulation for consumption and the share. It shows the percentage ${ }^{36}$ with increases in the consumption of husband and the wife, and the share

\footnotetext{
36 Per household 12500 replications were done.
} 
of the husband and the wife due to changing the properties of the tax system. It should be noted that household members that do not experience an increase in consumption do not necessarily experience a decrease. For the restricted sharing rules married women do worse than unmarried women, mainly because the differences in participation rates between the groups. Comparing the restricted sharing rules with the unrestricted rules, we notably see that husbands do better according to the flexible rules. The main reason is that the decrease in the tax allowance makes the husband withdraw funds from his wife. On the other hand, the decrease in marginal tax rates of husbands increases the share of the wife. That is why in total we see in the flexible sharing rule variants relatively more women with an increase in their consumption than in the restricted variants. The fact that husbands decrease transfers to their wives need not necessarily be seen as something negative, but also indicates that women are induced to rely more on their own income sources. Table 8 shows the labour supply responses for women. Depending on the specification, participation increases from 0.3 to 1.2 percentage points. Hours per week increase from 0.2 to 0.6 . These effects are not very big, and therefore looking at differences across specifications is not very meaningful. It is interesting, though, that the flexible sharing rules show bigger increases in female participation, notably for unmarried women. This may be related to the withdrawal of funds by husbands from their wives.

\section{Conclusions}

We specified a discrete hours choice model that incorporates income taxation, individual preferences, and income sharing between partners. The identification of the sharing rule parameters was achieved by using data on both men and women within couples. Our estimation strategy deals with the coherency problem. This allows us to estimate the model without a priori imposing assumptions like monotonicity of preferences and a convex budget set. We estimated model specifications with restricted sharing mechanisms, one of which implies income pooling, and more flexible specifications, with different measures for relative income of partners within a household.

We evaluated the variants by analyzing behavioural outcomes, like elasticities and in- 
come allocation between partners. Different specifications do not always lead to different conclusions for female own wage elasticities of working hours and participation: a restricted variant with income pooling shows similar values for elasticities as the flexible specifications. This outcome may change if cross wage effects of partners had more sizable impacts.

The most notable differences are found for the income allocation between partners. Flexible specifications show a tendency of husbands to assign an increase in their wage rate or in the household's non-labour income to their wives. This asymmetry in intrahousehold income allocation cannot be explained by a restricted variant with income pooling.

We simulated the effects of a tax reform, introduced in the year 2001. The reform is meant to create additional incentives for participation by decreasing tax allowances, especially for the non-employed, and decreasing marginal tax rates. One of the consequences of lower tax allowances is that men withdraw funds from their partner. Variants with a restricted sharing rule are not flexible enough to capture this implication for intrahousehold allocation. Nevertheless more women gain according to the flexible sharing rules, compared to the restricted variants, since the decrease in marginal tax rates for some women affects both their own wages (direct effect) and the wages of their husbands, which in turn positively effects income transfers from husband to wife.

The results show how various tax policies influence intrahousehold allocation. Taxing the primary earner, usually the husband, more heavily leads to a reduction of intrahousehold transfers from husband to wife, which could create additional incentives for the wife to work. However, the present estimates showed that cross wage elasticities of the husband's wages on female labour supply were negative but low. A combination of this policy with a decrease in marginal tax rates for the secondary earner could be more effective than a simple decrease in overall marginal tax rates. Similarly, a decrease in tax allowances reduces transfers from husband to wife, creating more incentives for the wife, that may be further increased by a decrease in tax rates of secondary earners. ${ }^{37}$

\footnotetext{
37 Note that the effectiveness of taxing secondary earners not just comes from the higher own wage elasticity of labour supply of women, but the intrahousehold allocation mechanism provides an additional incentive for different tax rates for primary and secondary earners. In a different and theoretical model context that also includes family bargaining, Alesina et al. (2011) show that incorporating family bargaining adds to the explanation of the potential effectiveness of gender-based taxation.
} 
The limited impact of the 2001 reform can be explained by the opposing effects of the components of this reform. Total tax allowances were lowered, but at the same time marginal tax rates were smaller than or equal as before for both primary and secondary earners. The incentive to decrease intrahousehold transfers to the wife due to lower tax allowances were therefore partly offset by the incentive to increase transfers to the wife due to higher after tax wage rates. This particular combination may have depressed the total response of female labor supply to the tax policy. Over all, the intrahousehold allocation mechanism that we

detected shows that the effectiveness of particular tax policies may be enhanced by the intrahousehold allocation mechanism if the incentives work in the appropriate direction.

\section{References}

Alesina, A., A. Ichino, and L. Karabarbounis (2011), Gender-based taxation and the division of family chores, American Economic Journal: Economic Policy 3, pp. $1-40$.

Apps, P. and R. Rees (1988), Taxation and the household, Journal of Public Economics, Vol. 35, pp. 355-369.

Bargain, O. and N. Moreau (2003), Is the collective model of labor supply useful for tax policy analysis? A simulation exercise. CESifo Working Paper No. 1052.

Beninger, D. and F. Laisney (2002), Comparison between Unitary and Collective Models of Household Labor Supply with Taxation, working paper.

Bloemen, H.G. (2010), Am Empirical Model of Collective Household Labour Supply with Nonparticipation, Economic Journal, Vol. 120, pp. 183-214.

Bloemen, H.G, and A. Kapteyn (2008), The Estimation of Utility Consistent Labor Supply Models by means of Simulated Scores, Journal of Applied Econometrics, Vol. 23, pp. 395-422.

Blundell, R, P.A. Chiappori, T. Magnac and C. Meghir (2007), Collective labor supply: heterogeneity and nonparticipation, Review of Economic Studies, 
Vol. 74, No. 2, pp. 417-445.

Blundell, R, A. Duncan, J. McCrae and C. Meghir (1999), Evaluating inwork benefit reform: the working families tax credit in the UK, mimeo, London, Institute for Fiscal Studies.

Blundell, R, and T. MaCurdy (1999), Labor supply: a review of alternative approaches, in: O. Ashenfelter and D. Card (eds.), Handbook of Labor Economics, Vol. 3, pp. 1559-1695.

Chiappori, P.A. (1988), Rational Household Labor Supply, Econometrica, Vol. 56, pp. 63-89.

Chiappori, P.A. (1992), Collective Labor Supply and Welfare, Journal of Political Economy, Vol. 100, pp. 437-467.

Chiappori, P.A. (1997), Introducing Household Production in Collective Models of Labor Supply, Journal of Political Economy, Vol. 105, No. 1, pp. 191-209.

Chiappori, P.A, R. Blundell and C. Meghir (2005), Collective Labor Supply with Children, Journal of Political Economy, Vol. 113, No. 6, pp. 1277-1306.

Chiappori, P.A, B. Fortin and G. Lacroix (2002), Marriage Market, Divorce Legislation, and Household Labor Supply, Journal of Political Economy, Vol. 110, no. 11 , pp. $37-72$.

Donni, O. (2003), Collective Household Labor Supply: Nonparticipation and Income Taxation, Journal of Public Economics, Vol. 87, pp. 1179-1198.

Fortin, B. and G. Lacroix (1997), A test of the Unitary and Collective Models of Household Labor Supply, Economic Journal, Vol. 107, pp. 933-955.

Hausman, J. and P. Ruud (1984), Family labor supply with taxes, American Economic Review, Vol. 74, pp. 242-248.

Hoynes, H. (1996), Welfare transfers in two-parent families: labor supply and welfare participation under ADDC-UP, Econometrica, Vol. 64. pp. 295-332. 
Keane, M, and R. Moffit (1998), A structural model of multiple welfare program participation and labor supply, International Economic Review, Vol. 39, No. 3, pp. 553-589.

Manser, M. and M. Brown (1980), Marriage and household decision-making: a bargaining analysis, International Economic Review, Vol. 1, No. 6, pp. 31-44.

McElroy, M.B. and M.J Horney (1981), Nash-bargained household decisions: towards a generalization of the theory of demand, International Economic Review, Vol. 22, No. 2, pp. 333-349.

Thomas, D. (1990), Intra household resource allocation: an inferential approach, Journal of Human Resources, Vol. 25, nr. 4, pp. 635-664.

Van Soest, A.H.O. (1995), Structural Models of Family Labor Supply: A Discrete Choice Approach, Journal of Human Resources, Vol. 30, No. 1, pp. 63-88.

Van Soest, A.H.O. and M. Das (2001), Family Labor Supply and Proposed Tax Reforms in the Netherlands, De Economist, Vol. 149, No. 2, pp. 191-218.

Vermeulen, F. (2002), Collective Household Models: Principles and Main Results, Journal of Economic Surveys, Vol. 16, No. 4, pp. 533-564.

Vermeulen, F. (2006), A Collective Model for Female Labour Supply with Nonparticipation and Taxation, Journal of Population Economics, Vol. 19, pp. 99-118.

Vermeulen, F., O. Bargain, M. Beblo, D. Beninger, R. Blundell, R. Carrasco, M. Chiuri, F. Laisney, V. Lachene, N. Moreau, M. Myck, and J. Ruiz-Castillo (2006), Collective models of labor supply with nonconvex budget sets and nonparticipation: A calibration approach, Review of Economics of the Household, Vol. 4, No. 2, pp. 113-127. 
Table 1: The Dutch tax system: general tax credits, marginal tax rate 1st bracket, and bracket bounds

\begin{tabular}{|c|c|c|c|c|c|}
\hline Year & $\begin{array}{r}\text { transferable } \\
\text { amount } \\
\text { tax credit }\end{array}$ & $\begin{array}{r}\text { non-transferable } \\
\text { amount } \\
\text { tax credit }\end{array}$ & $\begin{array}{l}\text { marginal tax } \\
\text { rate } 1 \text { st bracket }\end{array}$ & $\begin{array}{l}\text { upper bound } \\
\text { 1st bracket= } \\
\text { lwb. } 2 \text { nd br. }\end{array}$ & $\begin{array}{l}\text { upper bound } \\
\text { 2nd bracket= } \\
\text { lwb. 3rd br. }\end{array}$ \\
\hline 1990 & 4568 & 0 & $31.5 \%$ & 42123 & 84245 \\
\hline 1991 & 4660 & 0 & $35.75 \%$ & 42966 & 85930 \\
\hline 1992 & 5225 & 0 & $38.55 \%$ & 42966 & 85930 \\
\hline 1993 & 5769 & 0 & $38.4 \%$ & 43267 & 86532 \\
\hline 1994 & 5925 & 0 & $38.125 \%$ & 43267 & 86532 \\
\hline 1995 & 6074 & 0 & $37.65 \%$ & 44349 & 88696 \\
\hline 1996 & 7003 & 0 & $37.5 \%$ & 45325 & 92773 \\
\hline 1997 & 7102 & 0 & $37.3 \%$ & 45960 & 97422 \\
\hline 1998 & 8207 & 410 & $36.35 \%$ & 47184 & 103774 \\
\hline 1999 & 8380 & 419 & $\begin{array}{l}35.75 \% / \\
/ 37.05 \%\end{array}$ & $15000 / 48175$ & 105954 \\
\hline 2000 & 8523 & 427 & $\begin{array}{r}33.9 \% / \\
/ 37.95 \% \\
\end{array}$ & $15255 / 48994$ & 107756 \\
\hline 2001 & $\begin{array}{r}\text { general } \\
\text { tax credit } \\
3473\end{array}$ & $\begin{array}{r}\text { labour } \\
\text { tax credit } \\
2027\end{array}$ & $\begin{array}{l}32.35 \% / \\
37.60 \% / \\
\end{array}$ & $32769 / 59520$ & 102052 \\
\hline \multicolumn{6}{|c|}{$\begin{array}{l}\text { Amounts in Dutch Guilders } \\
\text { Marginal tax rates of the } 2 \text { nd and 3rd bracket: } 50 \% \text { and } 60 \%(1990-2000) ; 42 \% \text { and } 52 \% \text { (2001) } \\
\text { from } 1999 \text { on: first bracket split in two } \\
\text { bracket bounds apply to income minus tax credit }\end{array}$} \\
\hline
\end{tabular}


Table 2: descriptive statistics of the pooled data: 8049 observations

\begin{tabular}{|c|c|c|c|}
\hline Variable & Husband & & Wife \\
\hline \multicolumn{4}{|l|}{ Employment status } \\
\hline Employed & $84.5 \%$ & & $70.3 \%$ \\
\hline Not Employed & $15.5 \%$ & & $29.7 \%$ \\
\hline \multicolumn{4}{|l|}{ Education level } \\
\hline Primary & $7.3 \%$ & & $11.2 \%$ \\
\hline Lower vocational & $16.0 \%$ & & $23.4 \%$ \\
\hline Intermediate & $49.3 \%$ & & $42.5 \%$ \\
\hline Higher Vocational & $20.0 \%$ & & $18.2 \%$ \\
\hline University degree & $7.0 \%$ & & $4.4 \%$ \\
\hline \multicolumn{4}{|l|}{ Education sector } \\
\hline Technical & $34.4 \%$ & & $5.3 \%$ \\
\hline Economic/administrative & $25.9 \%$ & & $24.5 \%$ \\
\hline General (not specialized) & $18.1 \%$ & & $30.2 \%$ \\
\hline Services & $21.5 \%$ & & $40.0 \%$ \\
\hline \multicolumn{4}{|l|}{ Weekly working hours } \\
\hline \# Observations & $\mathrm{n}=6618$ & & $\mathrm{n}=5408$ \\
\hline Mean & 39.4 & & 30.9 \\
\hline (Standard deviation) & $(7.9)$ & & $(10.8)$ \\
\hline \multicolumn{4}{|l|}{ Hourly gross wage rates } \\
\hline \# Observations & $\mathrm{n}=6100$ & & $\mathrm{n}=5029$ \\
\hline Mean (Guilders) & 30.2 & & 24.7 \\
\hline (Standard deviation) & $(10.0)$ & & $(8.4)$ \\
\hline \multicolumn{4}{|l|}{ Age } \\
\hline Mean & 40.8 & & 38.7 \\
\hline (Standard deviation) & $(12.4)$ & & $(12.5)$ \\
\hline \multicolumn{4}{|l|}{ Household level variables } \\
\hline \multicolumn{4}{|l|}{ Non-labour income } \\
\hline \multicolumn{4}{|l|}{ Household level, weekly } \\
\hline Mean (guilders) & & 37.7 & \\
\hline Standard deviation & & $(94.8)$ & \\
\hline \multicolumn{4}{|l|}{ Employment status } \\
\hline Both partners working & & $64.3 \%$ & \\
\hline Husband working, wife not & & $20.2 \%$ & \\
\hline Wife working, husband not & & $6.0 \%$ & \\
\hline Both not working & & $9.5 \%$ & \\
\hline \multicolumn{4}{|l|}{ Marital status } \\
\hline Married & & $69.1 \%$ & \\
\hline
\end{tabular}


Table 3: Estimates of the utility parameters

\begin{tabular}{|c|c|c|c|c|}
\hline & \multicolumn{4}{|c|}{ Model variant: } \\
\hline & \multicolumn{2}{|c|}{$\begin{array}{c}\text { Restricted } \\
\text { sharing rule }\end{array}$} & \multicolumn{2}{|c|}{$\begin{array}{l}\text { Unrestricted } \\
\text { sharing rule }\end{array}$} \\
\hline & share & share & share & share \\
\hline & $\rho_{\text {half }}$ & $\rho_{\text {pool }}$ & eqn. $(20)$ & eqn. $(20)$ \\
\hline & eqn. (24) & eqn. $(25)$ & with $D$ eqn. (21) & with $D$ eqn. (22) \\
\hline \multicolumn{5}{|l|}{ Parameters Husband } \\
\hline \multirow{2}{*}{$\beta_{0, h h}^{m}, \ln \left(1-h_{m}\right)^{2}$} & $-121.7^{* *}$ & $-118.3^{* *}$ & $-121.8^{* *}$ & $-124.2^{* *}$ \\
\hline & $(13.5)$ & $(13.1)$ & $(22.6)$ & $(21.1)$ \\
\hline \multirow{2}{*}{$\beta_{c h}^{m}, \ln \left(T-h_{m}\right) C_{m}$} & $-6.7^{* *}$ & $-5.2^{* *}$ & $-29.2^{* *}$ & $-34.3^{* *}$ \\
\hline & $(1.8)$ & $(1.4)$ & $(4.6)$ & $(4.7)$ \\
\hline \multirow[t]{2}{*}{$\beta_{c}^{m}, C_{m}$} & $34.7^{* *}$ & $27.1^{* *}$ & $150.2^{* *}$ & $176.1^{* *}$ \\
\hline & $(8.8)$ & $(6.7)$ & $(23.8)$ & $(23.9)$ \\
\hline \multirow[t]{2}{*}{$\beta_{c c}^{m}, C_{m}^{2}$} & -0.0003 & -0.0003 & $-0.071^{*}$ & $-0.14^{*}$ \\
\hline & $(0.002)$ & $(0.003)$ & $(0.042)$ & $(0.078)$ \\
\hline \multirow[t]{2}{*}{$\beta_{0 h}^{m}, \ln \left(T-h_{m}\right)$} & $1055.4^{* *}$ & 1020.4 & $1055.1^{* *}$ & $1055.3^{* *}$ \\
\hline & $(371.8)$ & $(682.0)$ & $(227.7)$ & $(213.0)$ \\
\hline$\%$ with $M U_{C}>0$ & 100 & 100 & 100 & 100 \\
\hline \multicolumn{5}{|l|}{ Parameters Wife } \\
\hline \multirow[t]{2}{*}{$\beta_{0, h h}^{f}, \ln \left(T-h_{f}\right)^{2}$} & $-103.5^{* *}$ & $-106.2^{* *}$ & $-102.3^{* *}$ & $-102.0^{* *}$ \\
\hline & (13.8) & $(13.9)$ & (14.8) & $(14.6)$ \\
\hline \multirow[t]{2}{*}{$\beta_{c h}^{f}, \ln \left(T-h_{f}\right) C_{f}$} & $-7.6^{* *}$ & $-8.2^{* *}$ & $-1.7^{* *}$ & $-2.3^{* *}$ \\
\hline & $(2.0)$ & $(1.3)$ & $(0.6)$ & $(0.7)$ \\
\hline \multirow[t]{2}{*}{$\beta_{c}^{f}, C_{f}$} & $42.2^{* *}$ & $43.0 * *$ & $9.8^{* *}$ & $13.0^{* *}$ \\
\hline & $(9.8)$ & $(7.0)$ & $(3.0)$ & $(3.4)$ \\
\hline \multirow[t]{2}{*}{$\beta_{c c}^{f}, C_{f}^{2}$} & $0.46^{* *}$ & 0.07 & $0.06^{* *}$ & $0.11^{* *}$ \\
\hline & $(0.20)$ & $(0.06)$ & $(0.02)$ & $(0.03)$ \\
\hline \multirow[t]{2}{*}{$\beta_{0 h}^{f}, \ln \left(T-h_{f}\right)$} & $981.7^{* *}$ & $947.8^{* *}$ & $981.3^{* *}$ & $981.7^{* *}$ \\
\hline & $(138.6)$ & $(147.1)$ & $(148.3)$ & $(146.5)$ \\
\hline$\%$ with $M U_{C}>0$ & 98.4 & 99.7 & 97.8 & 98.4 \\
\hline \multicolumn{5}{|c|}{$* *:$ significant at $5 \%$ level, $*: 10 \%$ level } \\
\hline \multicolumn{5}{|c|}{ Consumption divided by 1000 , so parameter measure the impact of $C_{j} / 1000, j=m, f$} \\
\hline
\end{tabular}


Table 4: Estimates of the sharing rule

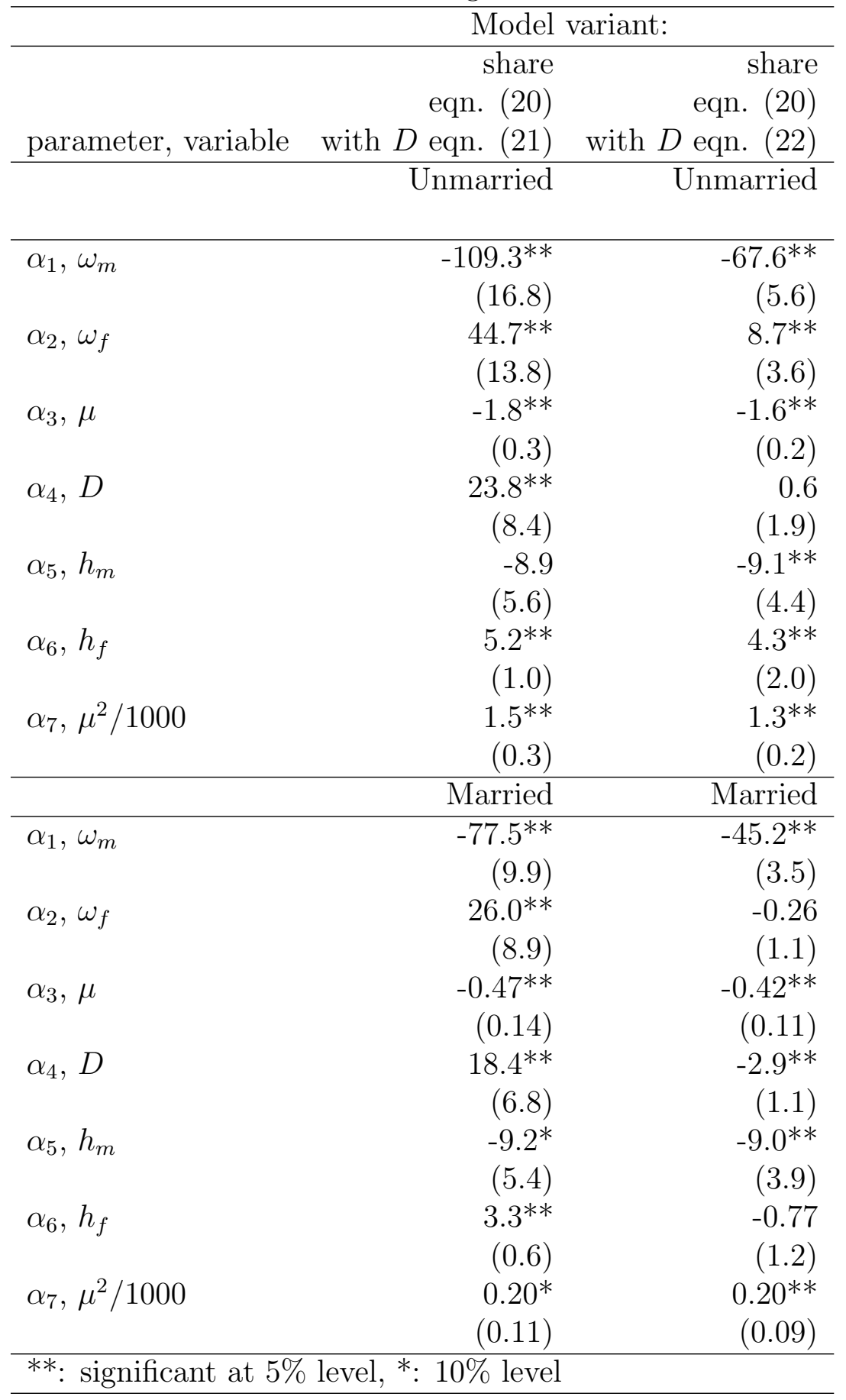


Table 5: Elasticities of working hours and participation

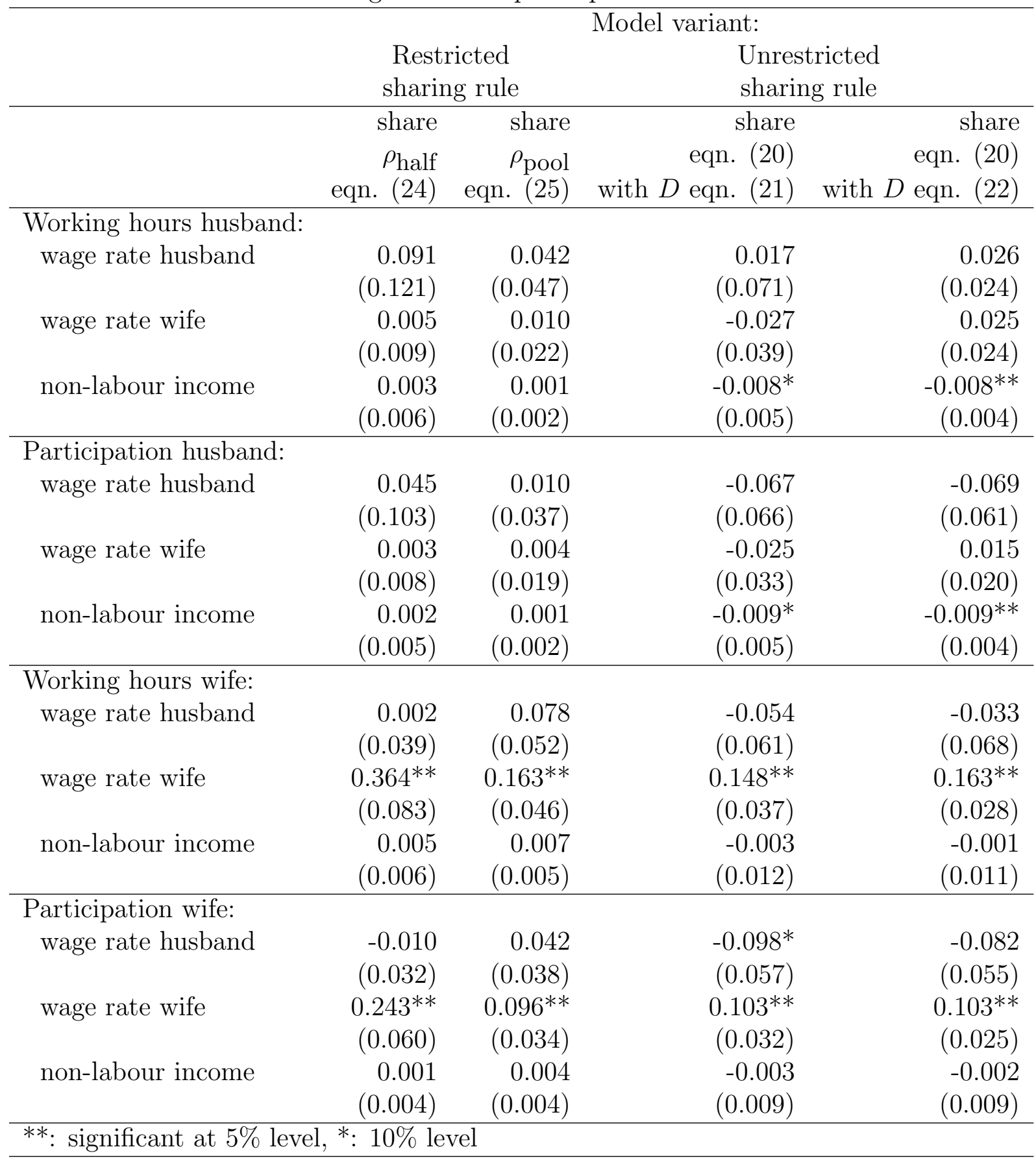


Table 6a: Effects of changes in wage rates and non-labour income on consumption, the sharing rule, and utility

Restricted sharing rule

\begin{tabular}{|c|c|c|c|}
\hline \multicolumn{4}{|c|}{ Variant: Restricted sharing rule $\rho_{\text {half }}$, eqn. (24) } \\
\hline percentage & $1 \%$ increase & $1 \%$ increase & 1 guilder \\
\hline with & gross wage & gross wage & increase \\
\hline increase & rate husband & rate wife & non-labour \\
\hline in: & & & income \\
\hline \multicolumn{4}{|c|}{ unmarried subsample } \\
\hline consumption husband & 91.4 & 1.1 & 99.9 \\
\hline consumption wife & 6.6 & 87.9 & 99.9 \\
\hline $\operatorname{share} \operatorname{husband}\left(\rho_{m}\right)$ & 2.4 & 1.1 & 99.9 \\
\hline share wife $\left(\rho_{f}\right)$ & 2.4 & 1.1 & 99.9 \\
\hline \multicolumn{4}{|c|}{ married subsample } \\
\hline consumption husband & 78.3 & 0.9 & 99.9 \\
\hline consumption wife & 8.1 & 60.3 & 99.9 \\
\hline share husband $\left(\rho_{m}\right)$ & 2.9 & 0.9 & 99.9 \\
\hline share wife $\left(\rho_{f}\right)$ & 2.9 & 0.9 & 99.9 \\
\hline \multicolumn{4}{|c|}{ Variant: Restricted sharing rule $\rho_{\text {pool }}$ eqn. (25) (pooling) } \\
\hline percentage & $1 \%$ increase & $1 \%$ increase & 1 guilder \\
\hline with & gross wage & gross wage & increase \\
\hline positive & rate husband & rate wife & non-labour \\
\hline change in: & & & income \\
\hline \multicolumn{4}{|c|}{ unmarried subsample } \\
\hline consumption husband & 93.0 & 88.9 & 99.9 \\
\hline consumption wife & 93.0 & 88.8 & 99.9 \\
\hline $\operatorname{share} \operatorname{husband}\left(\rho_{m}\right)$ & 3.9 & 88.9 & 99.9 \\
\hline share wife $\left(\rho_{f}\right)$ & 90.8 & 1.2 & 99.7 \\
\hline \multicolumn{4}{|c|}{ married subsample } \\
\hline consumption husband & 79.9 & 61.0 & 99.9 \\
\hline consumption wife & 79.9 & 60.9 & 99.9 \\
\hline share husband $\left(\rho_{m}\right)$ & 4.9 & 61.0 & 99.9 \\
\hline share wife $\left(\rho_{f}\right)$ & 76.9 & 0.8 & 99.6 \\
\hline
\end{tabular}


Table 6b: Effects of changes in wage rates and non-labour income on consumption, the sharing rule, and utility

Flexible sharing rule

\begin{tabular}{|c|c|c|c|}
\hline \multicolumn{4}{|c|}{ Variant: Flexible sharing rule eqn. (20) with $D$ eqn. (21) } \\
\hline percentage & $1 \%$ increase & $1 \%$ increase & 1 guilder \\
\hline with & gross wage & gross wage & increase \\
\hline $\begin{array}{l}\text { increase } \\
\text { in. }\end{array}$ & rate husband & rate wife & non-labour \\
\hline \multicolumn{4}{|c|}{ unmarried subsample } \\
\hline consumption husband & 1.6 & 59.2 & 3.0 \\
\hline consumption wife & 100.0 & 90.3 & 99.2 \\
\hline share husband $\left(\rho_{m}\right)$ & 0.0 & 59.2 & 3.0 \\
\hline share wife $\left(\rho_{f}\right)$ & 100.0 & 40.9 & 99.2 \\
\hline \multicolumn{4}{|c|}{ married subsample } \\
\hline consumption husband & 12.0 & 41.6 & 0.0 \\
\hline consumption wife & 100.0 & 75.5 & 100.0 \\
\hline share husband $\left(\rho_{m}\right)$ & 0.0 & 41.6 & 0.0 \\
\hline share wife $\left(\rho_{f}\right)$ & 100.0 & 58.4 & 100.0 \\
\hline \multicolumn{4}{|c|}{ Variant: Flexible sharing rule eqn. (20) with $D$ eqn. (22) } \\
\hline percentage & $1 \%$ increase & $1 \%$ increase & 1 guilder \\
\hline with & gross wage & gross wage & increase \\
\hline positive & rate husband & rate wife & non-labour \\
\hline change in: & & & income \\
\hline \multicolumn{4}{|c|}{ unmarried subsample } \\
\hline consumption husband & 4.9 & 97.4 & 3.5 \\
\hline consumption wife & 94.6 & 87.3 & 97.4 \\
\hline share husband $\left(\rho_{m}\right)$ & 5.7 & 97.3 & 3.5 \\
\hline share wife $\left(\rho_{f}\right)$ & 95.2 & 2.7 & 98.9 \\
\hline \multicolumn{4}{|c|}{ married subsample } \\
\hline consumption husband & 13.9 & 97.2 & 1.0 \\
\hline consumption wife & 96.3 & 61.6 & 98.5 \\
\hline share husband $\left(\rho_{m}\right)$ & 6.0 & 97.2 & 1.0 \\
\hline share wife $\left(\rho_{f}\right)$ & 94.9 & 2.9 & 99.1 \\
\hline
\end{tabular}


Table 7: Changing the tax policy

Implications for sharing

\begin{tabular}{lcccr}
\hline & \multicolumn{4}{c}{ Model variant: } \\
& $\begin{array}{l}\text { Restricted } \\
\text { sharing rule: }\end{array}$ & $\begin{array}{c}\text { Unrestricted } \\
\text { sharing rule }\end{array}$ \\
\hline Percentage & $\rho_{\text {half }}$ & $\rho_{\text {pool }}$ & $D$ & $D$ \\
with & eqn. & eqn. & eqn. & eqn. \\
increase in: & $(24)$ & $(25)$ & $(21)$ & $(22)$ \\
\hline \multicolumn{4}{c}{ unmarried subsample } \\
\hline consumption husband & 46.1 & 41.3 & 76.1 & 84.4 \\
consumption wife & 47.1 & 41.0 & 44.0 & 46.3 \\
share husband & 3.5 & 9.3 & 53.6 & 51.2 \\
share wife & 3.5 & 13.2 & 26.1 & 21.5 \\
\hline \multicolumn{4}{c}{ married subsample } \\
\hline consumption husband & 45.3 & 32.4 & 67.0 & 76.5 \\
consumption wife & 37.7 & 32.0 & 45.3 & 47.3 \\
share husband & 5.7 & 8.2 & 35.7 & 34.9 \\
share wife & 5.7 & 13.8 & 26.8 & 26.7 \\
\hline
\end{tabular}

Table 8: Changing the tax policy

Implications for female labour supply

Model variant:

Restricted Unrestricted sharing rule: sharing rule

\begin{tabular}{|c|c|c|c|c|}
\hline $\begin{array}{l}\text { Change } \\
\text { in: }\end{array}$ & $\begin{array}{c}\rho_{\text {half }} \\
\text { eqn. } \\
(24)\end{array}$ & $\begin{array}{l}\rho_{\text {pool }} \\
\text { eqn. } \\
(25)\end{array}$ & $\begin{array}{r}D \\
\text { eqn. } \\
(21)\end{array}$ & $\begin{array}{r}D \\
\text { eqn. } \\
(22)\end{array}$ \\
\hline \multicolumn{5}{|c|}{ unmarried subsample } \\
\hline working hours & 0.6 & 0.2 & 0.4 & 0.4 \\
\hline participation & 0.8 & 0.3 & 1.2 & 1.2 \\
\hline \multicolumn{5}{|c|}{ married subsample } \\
\hline working hours & 0.5 & 0.2 & 0.3 & 0.4 \\
\hline participation & 1.0 & 0.5 & 1.0 & 1.4 \\
\hline
\end{tabular}

Working hours: change in average number per week

Participation: change in percentage points 


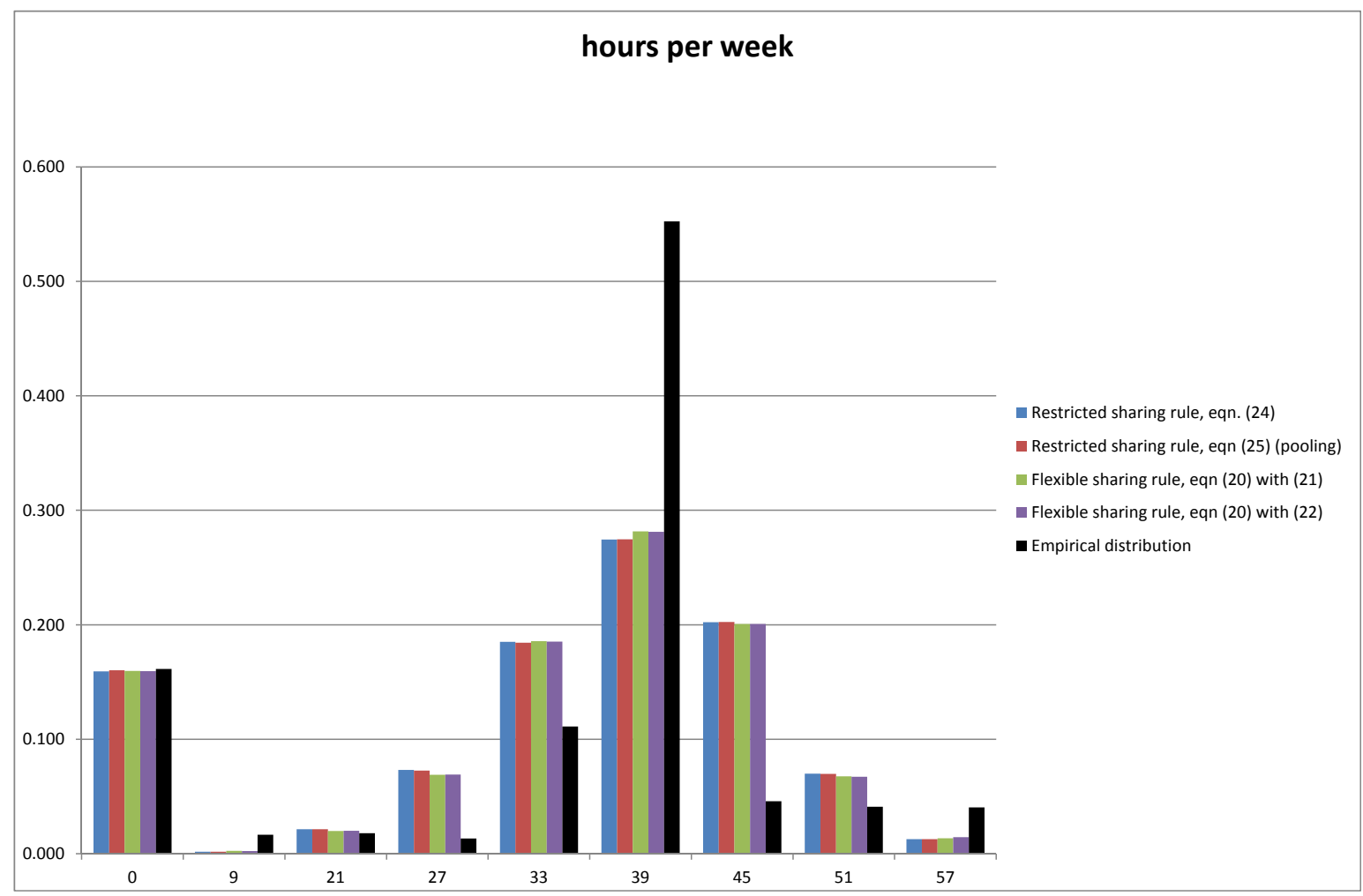

Figure 1: Distribution of weekly working hours of men 


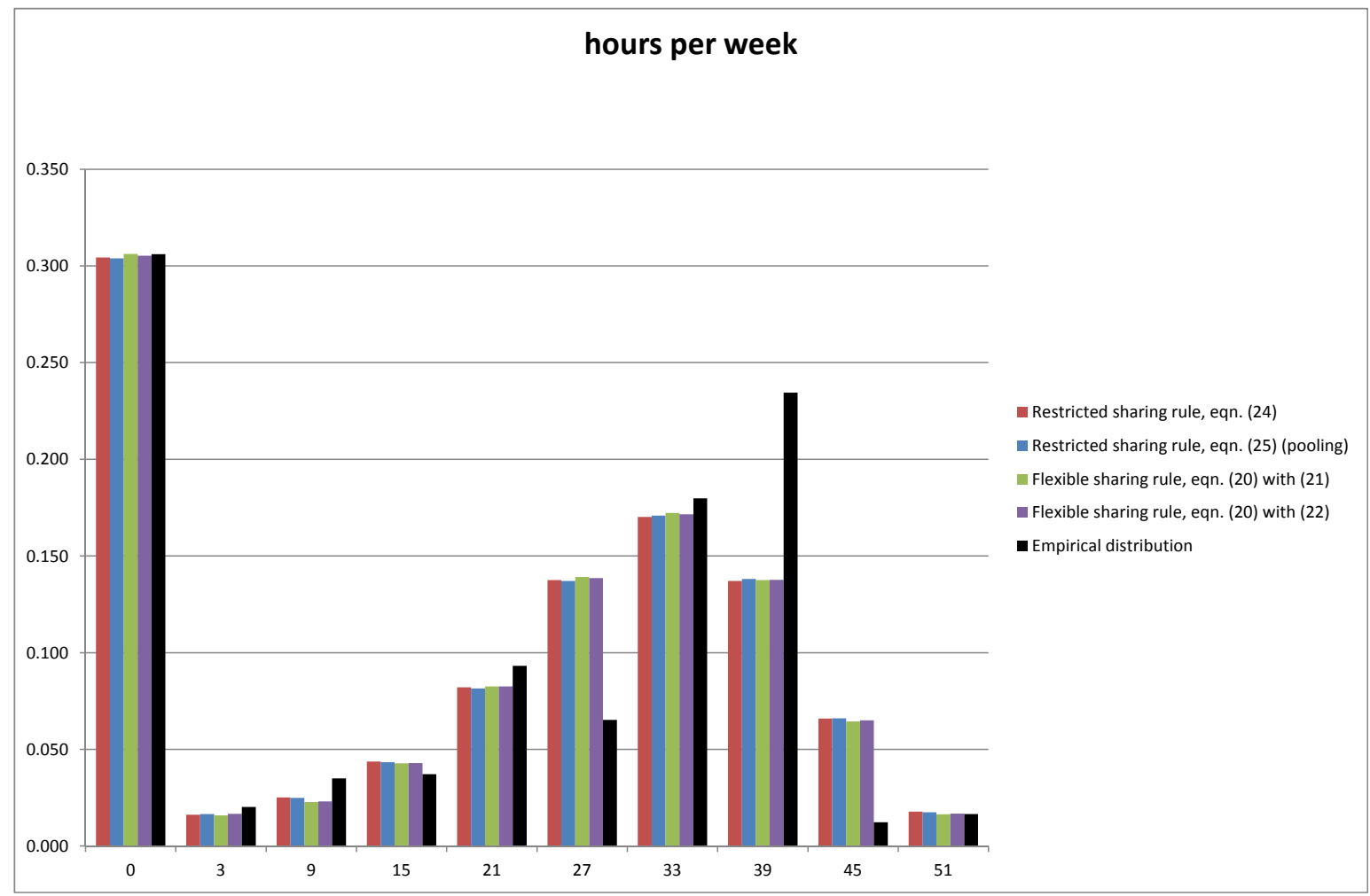

Figure 2: Distribution of weekly working hours of women 


\section{A The wage equation}

For individuals who do not work, or individuals who do work but have missing information on wages, the gross wage rate is not observed. We formulate the following equation for the gross wage rate:

$$
\ln w_{j}=\eta_{j}^{\prime} x_{j}+v_{j}, j=m, f
$$

In $(32) \eta_{j}$ is the parameter vector measuring the impact of the observed characteristics $x_{j}$ on the gross wage rate, whereas $v_{j}$ is a random error. We assume that $v_{j}$ follows a normal distribution with mean zero and covariance $\tau_{j}^{2}$. The parameters of the wage equations are estimated, correcting for selectivity. This is done by estimating the parameters of the wage equation simultaneously with a selection equation for the labour market state. Let $d_{j}$ be an indicator taking the value 1 if household member $j$ is employed and taking the value 0 if not. The selection equation is

$$
\begin{aligned}
& d_{j}^{*}=m_{j}^{\prime} \theta_{j}+l_{j}, j=m, f \\
& d_{j}=\iota\left(d_{j}^{*}>0\right)
\end{aligned}
$$

The error terms of the wage equations (32) and the selection equations (33) are assumed to be distributed according to the normal distribution:

$$
\left(\begin{array}{c}
l_{m} \\
l_{f} \\
v_{m} \\
v_{f}
\end{array}\right) \sim N\left(\left(\begin{array}{l}
0 \\
0 \\
0 \\
0
\end{array}\right),\left(\begin{array}{cccc}
1 & \rho_{m f} & \rho_{m 1} \tau_{m} & \rho_{m 2} \tau_{f} \\
\rho_{m f} & 1 & \rho_{f 1} \tau_{m} & \rho_{f 2} \tau_{f} \\
\rho_{m 1} \tau_{m} & \rho_{f 1} \tau_{m} & \tau_{m}^{2} & \tau_{m f} \\
\rho_{m 2} \tau_{f} & \rho_{f 2} \tau_{f} & \tau_{m f} & \tau_{f}^{2}
\end{array}\right)\right)
$$

which implicitly defines the correlation coefficients, variance parameters, and covariances between the error terms of the equations. The model parameters are estimated simultaneously by maximum likelihood.

Table A.1 contains the maximum-likelihood estimates of the parameters of the participation equation and Table A.2 contains the estimates of the wage equations of both husband and wife. In the wage equation we included a quadratic in the individual's age, dummy variables for the level of education, dummy variables for the type, or sector, of education, and time dummies. Note that the selection equation may be interpreted as an approximation of the 'reduced form' employment equation that follows from the structural model. In 
the employment equation we include all the variables that appear as taste shifters in the utility function, which are the age variables, the levels of education of both partners, and the marital status. Since the participation decision also depends on the wage of the partner, we also include the sector dummies of the partner in the employment equation. Because of the 'reduced form' nature of the selection equation it is hard to interpret the values of the estimates, and we do not devote much time discussing them. Nevertheless we may point at some interesting interactions of the partner's education on the employment status. We see that men with the lowest level of education have a lower probability of employment, and we see that men with wives who have any of the middle three education levels have a higher probability of being employed than men whose wives have either the lowest education level or university level. For the female employment status we do not find a significant impact of the husband's level of education, but we do see that her probability of being in employment increases monotonically with her own level of education. Since the employment equation is reduced form, we do not know whether this increasing pattern is due to the wage or due to preferences.

Table A.2 shows the estimates of the wage equations. Both the wage equation of the husband and of the wife show an increasing pattern in the level of education, and both men and women with an economic/administrative or a general type of education have higher wages than men and women working in technical or service sector. 
Table A1: ML Estimates of the employment equations

\begin{tabular}{lcccc}
\hline \multirow{2}{*}{ Variable } & \multicolumn{2}{c}{ Husband } & \multicolumn{2}{c}{ Wife } \\
& estimate & std. err. & estimate & std. err. \\
\hline intercept & -0.195 & 0.237 & $1.662^{* *}$ & 0.274 \\
$\log ($ age husband/17) & $7.858^{* *}$ & 0.741 & -0.978 & 0.609 \\
$\log ($ age husb./17) squared & $-5.588^{* *}$ & 0.450 & 0.430 & 0.374 \\
$\log ($ age wife/17) & -0.882 & 0.624 & $4.259^{* *}$ & 0.506 \\
$\log ($ age wife/17) squared & 0.316 & 0.408 & $-3.774^{* *}$ & 0.344 \\
Education level husband 1 & $-1.041^{* *}$ & 0.143 & $-0.575^{* *}$ & 0.116 \\
Education level husband 2 & $-0.578^{* *}$ & 0.114 & $-0.258^{* *}$ & 0.087 \\
Education level husband 3 & $-0.296^{* *}$ & 0.102 & $-0.189^{* *}$ & 0.078 \\
Education level husband 4 & -0.074 & 0.105 & $-0.275^{* *}$ & 0.080 \\
Education level wife 1 & -0.053 & 0.133 & $-0.859^{* *}$ & 0.128 \\
Education level wife 2 & $0.419^{* *}$ & 0.119 & $-0.732^{* *}$ & 0.115 \\
Education level wife 3 & $0.493^{* *}$ & 0.113 & $-0.458^{* *}$ & 0.108 \\
Education level wife 4 & $0.372^{* *}$ & 0.114 & $-0.247^{* *}$ & 0.110 \\
Married & $0.111^{*}$ & 0.065 & $-0.173^{* *}$ & 0.054 \\
Sector Technical husband & -0.035 & 0.057 & $0.118^{* *}$ & 0.048 \\
Sector Econ./adm. husband & 0.053 & 0.063 & $0.124^{* *}$ & 0.051 \\
Sector General husband & 0.025 & 0.082 & $0.223^{* *}$ & 0.068
\end{tabular}


Table A1: ML Estimates of the employment equations (ctd.)

\begin{tabular}{|c|c|c|c|c|}
\hline \multirow[b]{2}{*}{ Variable } & \multicolumn{2}{|c|}{ Husband } & \multicolumn{2}{|c|}{ Wife } \\
\hline & estimate & std. err. & estimate & std. err. \\
\hline Sector Technical wife & $-0.221^{* *}$ & 0.088 & $-0.164^{*}$ & 0.088 \\
\hline Sector Econ./adm. wife & -0.045 & 0.058 & $0.106^{* *}$ & 0.048 \\
\hline Sector General wife & $0.103 *$ & 0.060 & $-0.088^{*}$ & 0.047 \\
\hline$\mu / 1000$ & $-1.748^{* *}$ & 0.437 & $-1.259^{* *}$ & 0.388 \\
\hline$(\mu / 1000)^{2}$ & $1.334^{*}$ & 0.720 & $1.825^{* *}$ & 0.686 \\
\hline 1990 & $-0.515^{* *}$ & 0.102 & $-0.475^{* *}$ & 0.085 \\
\hline 1991 & $-0.260^{* *}$ & 0.107 & $-0.408^{* *}$ & 0.087 \\
\hline 1992 & $-0.329^{* *}$ & 0.105 & $-0.361^{* *}$ & 0.088 \\
\hline 1993 & $-0.368^{* *}$ & 0.106 & $-0.306^{* *}$ & 0.087 \\
\hline 1994 & $-0.383^{* *}$ & 0.105 & $-0.326^{* *}$ & 0.086 \\
\hline 1995 & $-0.199 *$ & 0.109 & $-0.214^{* *}$ & 0.087 \\
\hline 1996 & $-0.251^{* *}$ & 0.106 & $-0.240^{* *}$ & 0.084 \\
\hline 1997 & $-0.221^{* *}$ & 0.104 & $-0.175^{* *}$ & 0.085 \\
\hline 1998 & $-0.236^{* *}$ & 0.106 & -0.126 & 0.087 \\
\hline 1999 & $-0.216^{* *}$ & 0.108 & $-0.234^{* *}$ & 0.086 \\
\hline 2000 & -0.164 & 0.109 & -0.125 & 0.088 \\
\hline$\rho_{m f}$ & -0.171 & 0.458 & & \\
\hline$\rho_{m 1}$ & $0.491^{* *}$ & 0.004 & & \\
\hline$\rho_{m 2}$ & $-0.166^{*}$ & 0.095 & & \\
\hline$\rho_{f 1}$ & & & 0.060 & 0.107 \\
\hline$\rho_{f 2}$ & & & 0.026 & 0.129 \\
\hline
\end{tabular}


Table A2: ML Estimates of the Wage equations

\begin{tabular}{lcccc}
\hline \multirow{2}{*}{ Variable } & \multicolumn{2}{c}{ Husband } & \multicolumn{2}{c}{ Wife } \\
\hline intercept & $3.075^{* *}$ & 0.044 & $2.876^{* *}$ & 0.039 \\
$\log ($ age/17) & $1.168^{* *}$ & 0.114 & $1.671^{* *}$ & 0.103 \\
$\log ($ age/17) squared & $-0.425^{* *}$ & 0.081 & $-0.957^{* *}$ & 0.085 \\
Education level 1 & $-0.388^{* *}$ & 0.027 & $-0.395^{* *}$ & 0.033 \\
Education level 2 & $-0.389^{* *}$ & 0.020 & $-0.334^{* *}$ & 0.025 \\
Education level 3 & $-0.284^{* *}$ & 0.017 & $-0.235^{* *}$ & 0.022 \\
Education level 4 & $-0.141^{* *}$ & 0.018 & $-0.083^{* *}$ & 0.023 \\
Technical & 0.023 & 0.013 & 0.030 & 0.021 \\
Econ./adm. & & & & \\
General & $0.041^{* *}$ & 0.013 & $0.055^{* *}$ & 0.012 \\
& $0.038^{* *}$ & 0.015 & $0.079^{* *}$ & 0.013
\end{tabular}


Table A2: ML Estimates of the Wage equations (ctd.)

Husband Wife

\begin{tabular}{lcccc} 
Variable & estimate & std. err. & estimate & std. err. \\
\hline 1990 & $-0.183^{* *}$ & 0.024 & $-0.245^{* *}$ & 0.025 \\
1991 & $-0.118^{* *}$ & 0.022 & $-0.197^{* *}$ & 0.025 \\
1992 & $-0.089^{* *}$ & 0.023 & $-0.157^{* *}$ & 0.025 \\
1993 & $-0.064^{* *}$ & 0.022 & $-0.144^{* *}$ & 0.025 \\
1994 & $-0.135^{* *}$ & 0.022 & $-0.169^{* *}$ & 0.022 \\
1995 & $-0.118^{* *}$ & 0.022 & $-0.183^{* *}$ & 0.023 \\
1996 & $-0.122^{* *}$ & 0.021 & $-0.154^{* *}$ & 0.021 \\
1997 & $-0.108^{* *}$ & 0.021 & $-0.154^{* *}$ & 0.022 \\
1998 & $-0.104^{* *}$ & 0.022 & $-0.122^{* *}$ & 0.022 \\
1999 & $-0.075^{* *}$ & 0.023 & $-0.094^{* *}$ & 0.022 \\
2000 & -0.032 & 0.022 & $-0.064^{* *}$ & 0.023 \\
$\tau_{m}$ & $0.267^{* *}$ & 0.002 & & \\
$\tau_{f}$ & & & $0.288^{* *}$ & 0.002 \\
$\tau_{m f}$ & $0.077^{* *}$ & 0.014 & & \\
\hline$* *:$ significant at $5 \%$ & level, *: $10 \%$ level & \\
\hline
\end{tabular}




\section{B Parameter estimates: the taste shifters and model fit}

Tables B1 through B3 contain the estimates of the taste shifter parameters and fixed costs. For reasons of conciseness, we only comment on the two specifications with an unrestricted sharing rule. The parameter estimates are hard to interpret by themselves, but their impact becomes clear once we realize how they affect the marginal utility of leisure. The base

parameters of the marginal utility of leisure are $\beta_{0, h h}^{j}$ and $\beta_{0 h}^{j}, j=m, f$ (see Table 3 ). The parameters in Table B1 show the deviations from this base. We computed the marginal utility of leisure for working hours levels of 40 for men and 32 for women (which correspond to the average levels of working hours for employed men and women).

For men, the marginal utility of leisure is highest for men with the highest level of education. There is no monotonous pattern among the lower three levels. Their marginal utility level of leisure decreases with the education level of their wives. Married men have a lower marginal utility of leisure.

For women the marginal utility of leisure decreases with the husband's level of education, whereas it is lower for the highest educated women. The marginal utility of leisure seems to be somewhat lower for unmarried women.

The estimates of the age coefficients imply that for men the marginal utility of leisure increases with the age (at average age levels). For women, it decreases with age.

Table B3 shows that fixed costs for men are estimated inprecisely for the restricted variants of the sharing rule. For the other variants, fixed costs are higher for married men, but decrease with age. Men with any of the three lower education levels have higher fixed costs than the highest educated reference group. For married women, fixed costs are higher for married women. Fixed costs decrease with age but at a decreasing rate. The highest educated women have the lowest fixed costs.

Figures 1 and 2 show the simulated and empirical distribution function of male and female working hours. Even though we employ a discrete hours model, it is hard to predict the high peak at full time hours. The underlying utility function is a smooth function of working hours and as a consequence the simulated distribution functions are smooth as well, 
especially compared to the empirical distribution function. We could have obtained an optical better results by merging the hours categories 39 and 45 to one full time category (and merge other categories as well), but that comes at the cost of removing information. The lesson of importance that we can learn from the figures is that there is not so much difference in the fit of the empirical distribution functions, except that the peak at full time hours for the flexible variants is much higher. 
Table B1: Estimates of the 'structural model', the taste shifters, husband.

\begin{tabular}{|c|c|c|c|c|}
\hline \multirow[b]{5}{*}{ parameter, variable } & \multicolumn{4}{|c|}{ Model variant: } \\
\hline & \multicolumn{2}{|c|}{$\begin{array}{c}\text { Restricted } \\
\text { sharing rule }\end{array}$} & \multicolumn{2}{|c|}{$\begin{array}{l}\text { Unrestricted } \\
\text { sharing rule }\end{array}$} \\
\hline & share & share & share & share \\
\hline & $\rho_{\text {half }}$ & $\rho_{\text {pool }}$ & eqn. $(20)$ & eqn. (20) \\
\hline & eqn. $(24)$ & eqn. $(25)$ & with $D$ eqn. (21) & with $D$ eqn. (22) \\
\hline Parameters $\beta_{h h}^{m}:$ & & & & \\
\hline $\ln ($ age husband/17) & $\begin{array}{r}-81.0^{* *} \\
(36.8)\end{array}$ & $\begin{array}{r}-79.5^{* *} \\
(36.9)\end{array}$ & $\begin{array}{r}-81.6^{* *} \\
(36.3)\end{array}$ & $\begin{array}{r}-83.1^{* *} \\
(35.9)\end{array}$ \\
\hline $\ln ($ age husband/17) squared & $\begin{array}{r}124.0^{* *} \\
(22.8)\end{array}$ & $\begin{array}{r}128.3^{* *} \\
(22.8)\end{array}$ & $\begin{array}{r}124.1^{* *} \\
(22.5)\end{array}$ & $\begin{array}{r}124.5^{* *} \\
(22.2)\end{array}$ \\
\hline education level husband 1 & $\begin{array}{r}-19.7^{* *} \\
(7.2)\end{array}$ & $\begin{array}{r}-19.9^{* *} \\
(7.1)\end{array}$ & $\begin{array}{r}-21.9^{* *} \\
(7.2)\end{array}$ & $\begin{array}{r}-20.8^{* *} \\
(7.2)\end{array}$ \\
\hline education level husband 2 & $\begin{array}{r}-89.2^{* *} \\
(5.9)\end{array}$ & $\begin{array}{r}-89.8^{* *} \\
(5.8)\end{array}$ & $\begin{array}{r}-89.7^{* *} \\
(6.1)\end{array}$ & $\begin{array}{r}-88.1^{* *} \\
(6.0)\end{array}$ \\
\hline education level husband 3 & $\begin{array}{r}-55.9 * * \\
(3.7)\end{array}$ & $\begin{array}{r}-58.9^{* *} \\
(3.7)\end{array}$ & $\begin{array}{r}-56.8^{* *} \\
(3.8)\end{array}$ & $\begin{array}{r}-56.0^{* *} \\
(3.8)\end{array}$ \\
\hline education level wife 1 & $\begin{array}{r}-7.0^{*} \\
(4.1)\end{array}$ & $\begin{array}{r}-7.5^{*} \\
(4.1)\end{array}$ & $\begin{array}{r}-7.0^{*} \\
(4.3)\end{array}$ & $\begin{array}{r}-7.0^{*} \\
(4.4)\end{array}$ \\
\hline education level wife 2 & $\begin{array}{r}-15.9 * * \\
(3.1)\end{array}$ & $\begin{array}{r}-17.0 * * \\
(3.1)\end{array}$ & $\begin{array}{r}-15.9 * * \\
(3.2)\end{array}$ & $\begin{array}{r}-16.0^{* *} \\
(3.3)\end{array}$ \\
\hline education level wife 3 & $\begin{array}{r}-9.5^{* *} \\
(2.5)\end{array}$ & $\begin{array}{r}-9.7^{* *} \\
(2.5)\end{array}$ & $\begin{array}{r}-9.4^{* *} \\
(2.5)\end{array}$ & $\begin{array}{r}-9.5^{* *} \\
(2.6)\end{array}$ \\
\hline married & $\begin{array}{r}-29.7^{* *} \\
(4.3)\end{array}$ & $\begin{array}{r}-32.1^{* *} \\
(4.3)\end{array}$ & $\begin{array}{l}-29.4 \\
(22.4)\end{array}$ & $\begin{array}{l}-29.7^{*} \\
(17.8)\end{array}$ \\
\hline Parameters $\beta_{h}^{m}:$ & & & & \\
\hline $\ln ($ age husband/17) & $\begin{array}{r}756.3^{* *} \\
(326.5)\end{array}$ & $\begin{array}{r}737.3^{* *} \\
(326.1)\end{array}$ & $\begin{array}{r}756.4^{* *} \\
(329.0)\end{array}$ & $\begin{array}{r}756.9^{* *} \\
(328.9)\end{array}$ \\
\hline $\ln ($ age husband/17) squared & $\begin{array}{r}-1112.9^{* *} \\
(271.3)\end{array}$ & $\begin{array}{r}-1152.1^{* *} \\
(392.4)\end{array}$ & $\begin{array}{r}-1112.8^{* *} \\
(203.4)\end{array}$ & $\begin{array}{r}-1112.0^{* *} \\
(204.5)\end{array}$ \\
\hline education level husband 1 & $\begin{array}{r}127.4 \\
(182.6)\end{array}$ & $\begin{array}{r}131.1 \\
(293.7)\end{array}$ & $\begin{array}{r}127.2^{*} \\
(69.8)\end{array}$ & $\begin{array}{r}127.4^{*} \\
(69.6)\end{array}$ \\
\hline education level husband 2 & $\begin{array}{c}728.1^{*} \\
(371.7)\end{array}$ & $\begin{array}{r}737.9 \\
(630.8)\end{array}$ & $\begin{array}{r}728.0^{* *} \\
(67.3)\end{array}$ & $\begin{array}{r}728.2^{* *} \\
(67.7)\end{array}$ \\
\hline education level husband 3 & $\begin{array}{c}462.5^{* *} \\
(217.2)\end{array}$ & $\begin{array}{r}490.6 \\
(384.3)\end{array}$ & $\begin{array}{r}462.5^{* *} \\
(42.2)\end{array}$ & $\begin{array}{r}462.7^{* *} \\
(43.1)\end{array}$ \\
\hline education level wife 1 & $\begin{array}{r}70.5 \\
(40.8)\end{array}$ & $\begin{array}{r}75.2 \\
(40.6)\end{array}$ & $\begin{array}{r}70.5 \\
(42.8)\end{array}$ & $\begin{array}{r}70.5 \\
(43.7)\end{array}$ \\
\hline education level wife 2 & $\begin{array}{r}157.3^{* *} \\
(30.7)\end{array}$ & $\begin{array}{r}167.8^{* *} \\
(30.6)\end{array}$ & $\begin{array}{r}157.5^{* *} \\
(32.0)\end{array}$ & $\begin{array}{r}157.6^{* *} \\
(32.5)\end{array}$ \\
\hline education level wife 3 & $\begin{array}{r}92.4^{* *} \\
(24.3)\end{array}$ & $\begin{array}{r}94.2^{* *} \\
(24.3)\end{array}$ & $\begin{array}{c}92.3^{* *} \\
(25.2)\end{array}$ & $\begin{array}{r}92.4^{* *} \\
(25.6)\end{array}$ \\
\hline married & $\begin{array}{c}250.9 * * \\
(106.3)\end{array}$ & $\begin{array}{r}272.5 \\
(186.7)\end{array}$ & $\begin{array}{r}251.5 \\
(229.8)\end{array}$ & $\begin{array}{r}251.9 \\
(181.0)\end{array}$ \\
\hline$\sigma_{\nu, m}$ & $\begin{array}{r}0.92 \\
(2.0)\end{array}$ & $\begin{array}{r}0.09 \\
(2.0)\end{array}$ & $\begin{array}{r}0.22 \\
(1.6)\end{array}$ & $\begin{array}{r}0.67 \\
(1.6)\end{array}$ \\
\hline
\end{tabular}

**: significant at 5\% level, $*$ : $10 \%$ level 
Table B2: Estimates of the 'structural model', the taste shifters, wife.

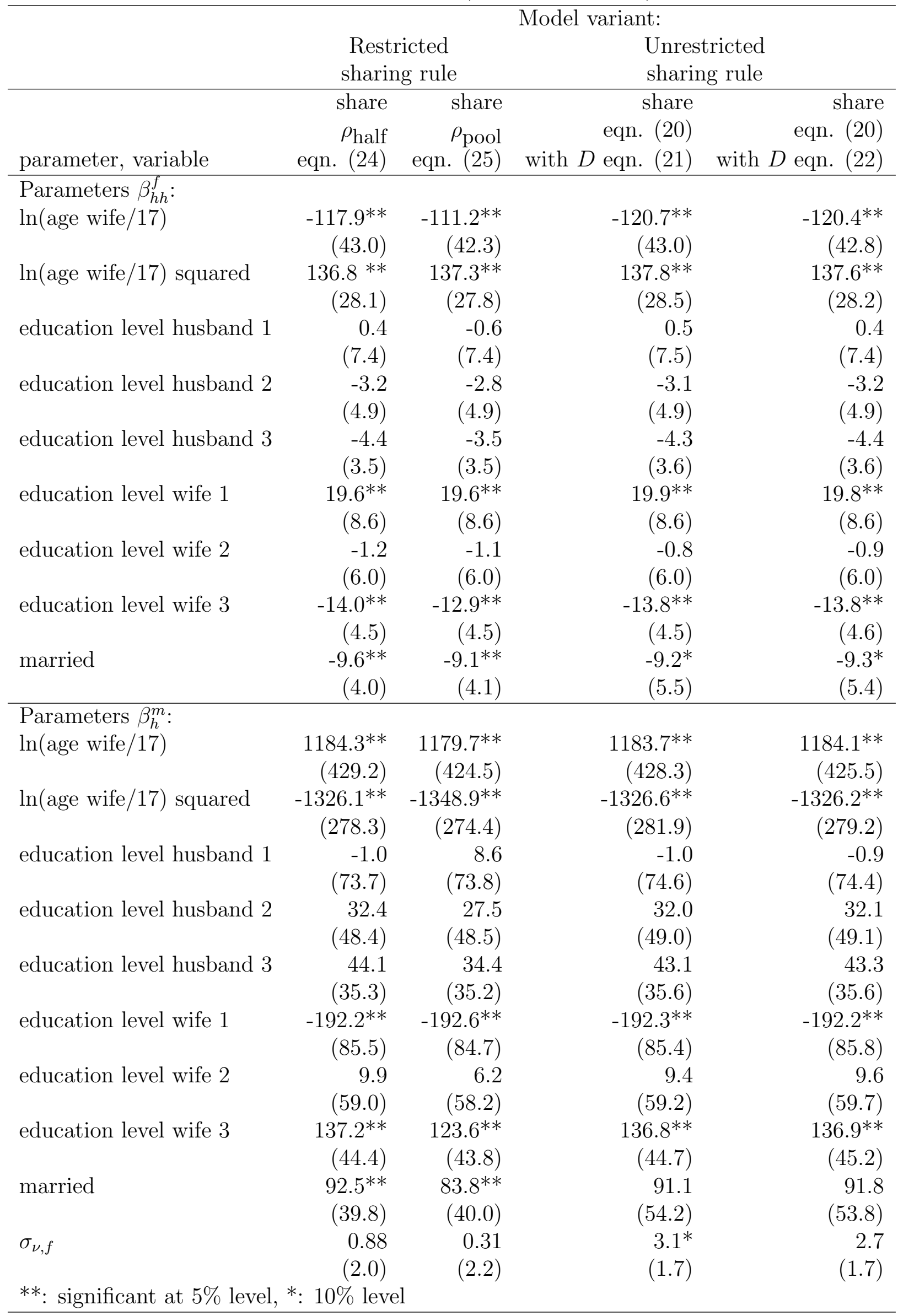


Table B3: Estimates of the fixed costs parameters

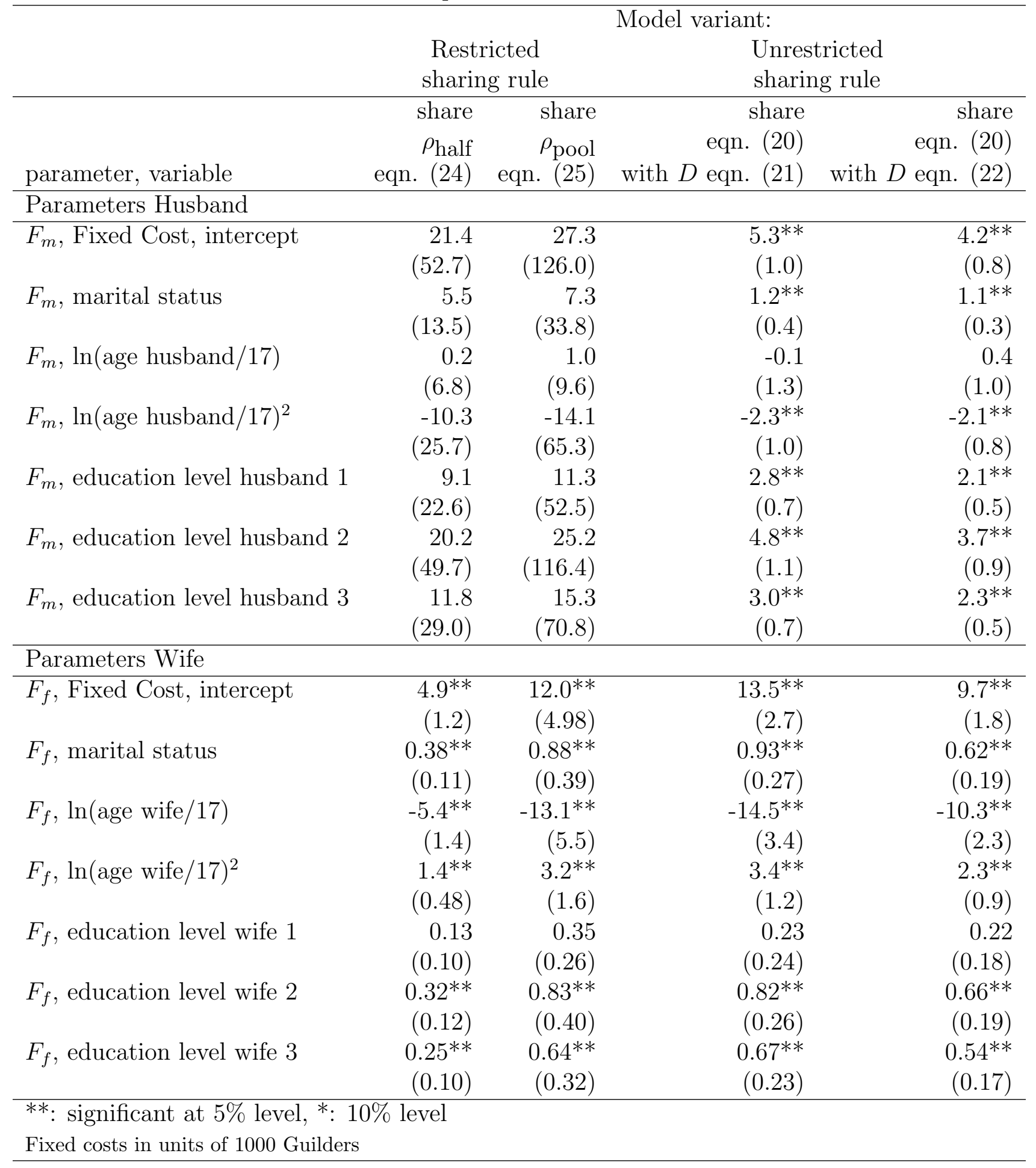

